\title{
Frictional Assignment, Part II: Infinite Horizon and Inequality*
}

\author{
Shouyong Shi \\ Department of Economics \\ University of Toronto \\ 150 St. George Street \\ Toronto, Ontario \\ Canada, M5S 3G7
}

This version: 2002 .

\begin{abstract}
In this paper I study the assignment between machines of heterogeneous qualities and workers of heterogeneous skills in an infinite-horizon economy with matching frictions. I characterize first the efficient assignment and then the decentralizing market equilibrium. The efficient allocation assigns a unique machine quality and market tightness to each skill. This efficient allocation is saddle-path stable and the assignment along the stable path is constant over time. The efficient assignment is not positively assortative when machine qualities and skills are not sufficiently complementary with each other. Moreover, efficient wage rates are increasing functions of the skill level when the assignment is positively assortative, but not always so when the assignment is not positively assortative. Nevertheless, the social value of workers always increases in the skill level.
\end{abstract}

Keywords: Matching; Frictions; Efficiency; Inequality.

* This is a significant extension of the second part of a paper circulated previously (Shi 1998). I thank Ken Burdett, Eric Fisher, George Neumann and especially Robert Shimer for comments and discussions. I have also benefited from comments given by workshop and conference participants at University of Hong Kong, Illinois (Urbana-Champaign), Indiana, Laval, Tilburg, Toronto, Canadian Economic Theory meeting (Toronto, 1999), Canadian Macroeconomic Study Group meeting (London, Ontario, 1999), and American Economic Association meeting (Boston, 2000). Financial support from the Social Sciences and Humanities Research Council of Canada is gratefully acknowledged. All remaining errors are mine alone. 


\section{Introduction}

In many markets each side contains heterogeneous agents and it is time consuming to match the two sides to produce "output". This two-sided matching problem, which I call a "frictional assignment", has attracted attention recently. ${ }^{1}$ Part of the reason is that frictional assignments differ significantly from the frictionless counterparts which Becker (1973) and Tinbergen (1951) examined in their seminal works. In particular, a frictional assignment can fail to be positively assortative (or positive for short). That is, an equilibrium with matching frictions may not necessarily assign the agents of high attributes to each other, even if the attributes are complementary in production. In this paper I characterize the efficient assignment with matching frictions and the corresponding decentralizing mechanism.

Previous papers on frictional assignments (see footnote 1) analyze only equilibrium allocations, which are generically inefficient. The reason is that those papers model search as an undirected process, by assuming an exogenous matching function that determines each agent's matching probability and an exogenous rule that splits the match surplus between agents ex post (after match). With undirected search, agents do not take into account the influence of their actions on their matching rates. So, the equilibrium fails to internalize matching externalities. Moreover, previous papers often examine a static environment, represented by either a one-period setup or a steady state, which leaves the dynamic features of the assignment unexplored.

In a precursor to the current paper (Shi 2001), I characterized the efficient assignment between machine qualities and workers' skills in a one-period economy with matching frictions. The main results were that the socially efficient assignment may be non-positively assortative (non-positive for short) and that there exists a market mechanism to decentralize the efficient allocation. In the current paper I extend the analysis to an infinite-horizon economy.

An infinite horizon is necessary for addressing the following issues. First, it is not clear whether the efficient assignment can still be non-positive. In a one-period frictional economy, a nonpositive assignment may be efficient because it can increase the matching success (or utilization) of skilled workers and high-quality machines. In an infinite horizon, however, the weight that efficiency puts on utilization is much smaller, because unmatched agents can continue to seek a match in the future. Second, intertemporal efficiency and dynamic stability are important issues in an infinite-horizon economy, because current and future matches are interdependent on each other. Expectations about the value of future matches affect the current assignment and, in turn, the current assignment affects the social value of future matches by changing the number of workers available for future matches. An efficient assignment must be efficient along the entire dynamic path, rather than being so in only the steady state or one particular period. Because of the intertemporal link, it is not even clear whether the efficient assignment is dynamically

\footnotetext{
${ }^{1}$ See Burdett and Coles (1997), Sattinger (1995), and Shimer and Smith (2000).
} 
stable or able to reach a steady state. Third, it is more challenging to characterize the market mechanism that decentralizes the efficient allocation along the entire time path.

To address these issues, I describe the efficient assignment as the decision problem of a fictional social planner, who maximizes the discounted sum of match surpluses. The planner faces the same matching frictions as the market does, namely, that it takes time to match the two sides and that there is no coordination between the matches. In particular, the social planner is not able to assign each individual machine to match with each individual worker, although he can assign a group of machines of the same quality to match with a group of workers of the same skill. This coordination failure implies that there are unmatched workers (and machines) in each period. To maximize the sum of social surpluses, the planner chooses the machine quality and the number of machines to match with each group of workers of the same skill. The matching function is endogenous.

I reformulate the social planner's problem recursively, where the efficient choices in each period are related to the next period only by the social value of future matches. This allows me to express the efficient choices in each period as functions of two variables - the number of unmatched workers at the beginning of the current period and the future value of workers. The dynamic system of these two variables characterizes the dynamics of the efficient allocation.

The dynamic system is saddle-path stable under rational expectations (perfect foresight). Moreover, the efficient assignment and the social value of workers are constant over time along the stable path. This stability result enables me to adapt the central results in Shi (2001) to an infinite-horizon economy. In particular, the efficient assignment is one-to-one between skills and machine qualities; the assignment is non-positive if skills and machine qualities are not sufficiently complementary with each other; and the market tightness varies systematically with the assignment. I then show that a market mechanism can decentralize the entire time path of the efficient assignment. A critical feature of the decentralizing mechanism is that firms post wages and machine qualities to direct the intended workers' search.

Dynamic stability is a result of the efficient trade-off between current and future matches. To understand this, it is useful to imagine that the economy is off the stable path in the sense that the social value of workers in the current period exceeds the steady state. In this case it is costly to delay a match to next period, because the delay foregoes the gain from a current match and suffers from discounting. For the efficient allocation to leave some workers for future matches, the future value of workers must exceed the steady state by sufficiently more than the current value of workers does. In fact, to compensate for the foregone gain from a current match, the gap between the social value of workers and its steady state must grow over time at a rate higher than the discounting rate. This violates the transversality condition required for intertemporal efficiency. Similarly, an assignment is not intertemporally efficient if the social value of workers 
in the current period falls below the steady state. ${ }^{2}$

The general contribution of this paper is the characterizations of the efficient assignment and the decentralizing mechanism in an economy with matching frictions. The specific contributions relative to the one-period setup in Shi (2001) are as follows. First, this paper provides a way to extend the intuitions and results to the infinite-horizon economy. Although the efficient assignment in this paper turns out to have similar properties to those in the one-period setup, the similarity is far from being obvious ex ante, given the restrictive nature of the one-period setup. Moreover, the similarity is deceiving, because the extension of the results relies heavily on saddle-path stability which is irrelevant in a static environment. As Shimer (2001b) testifies, saddle-path stability should not be presumed. Second, this paper yields strong predictions on the time patterns of the efficient assignment. The machine quality and market tightness assigned to each skill must be constant over time. So must be the wage for each skill in the market mechanism that decentralizes the efficient allocation. These predictions are useful for discussing how the assignment, wages, and inequality respond to shocks dynamically (see section 6).

The decentralizing mechanism in this paper features directed search, as each firm announces (and commits to) the wage path and the machine quality to attract the workers of a specific skill level. Thus, the paper belongs to the burgeoning literature originated in Peters (1991) and Montgomery (1991). ${ }^{3}$ In contrast to the current paper, however, other papers on directed search often assume that one or two sides of the market are homogeneous, thus missing the gist of the assignment problem. Notable exceptions are Peters and Siow (2002), Shi (forthcoming) and Shimer (2001a). However, these papers study one-period economies, which cannot address the dynamic issues raised in this paper.

There are other differences. Peters and Siow (2002) analyze the marriage market in which premarital investments serve as a device to direct the search of potential marriage partners. In contrast to the possibility of non-positive assignments here, they show that the efficient equilibrium has positively assortative matching according to premarital investment levels. Their result arises from the assumption that arbitrarily fine distinctions between the premarital investment levels can be publicly observed and rewarded by the market according to a non-stochastic return function. This assumption effectively eliminates the coordination failure among an agent's potential partners. In contrast, I assume realistically that the description of types (skills) is imprecise and so each skill level consists of a large number of workers. Thus, there is coordination

\footnotetext{
${ }^{2}$ The one-to-one nature of the efficient assignment is also important for saddle-path stability. A case for comparison is Shimer (2001b). By assuming an exogenous matching function, Shimer precludes the ability of the social planner to target only one skill to a particular machine quality. As a result, mixed matching occurs. Moreover, the threshold skill level that is acceptable for a match with a particular machine quality depends on expectations of the value of future matches. This dependence creates perpetual cycles in the efficient assignment. Such dependence does not exist with the one-to-one assignment.

${ }^{3}$ See Moen (1997), Burdett et al. (2001), Acemoglu and Shimer (1999), Cao and Shi (2000), and Julien et al. (2000).
} 
failure among the workers of the same skill, which makes utilization an important consideration for efficiency and allows a non-positive assignment to be efficient in some cases.

Shi (forthcoming) and Shimer (2001a) show that the efficient assignment can be mixed in a one-period setup. Such mixing arises because the assignment is allowed to be lexicographic. In particular, the social planner can assign both skills $s_{1}$ and $s_{2}$ to match with a machine (say, of quality $k$ ) but select a skill $s_{2}$ workers for the match only when no skill $s_{1}$ worker shows up at the match. Mixing occurs when some quality $k$ machines receive skill $s_{1}$ workers while others do not. In the current paper, I allow multiple-skill assignments to give probabilistic selection priorities, but not lexicographic ones, to the targeted skills. I will show in section 5 that this restriction implies that the efficient assignment must be one-to-one. I will also explain the reasons for excluding lexicographic selection rules.

Before describing the model, it is useful to mention that in this paper the distribution of machines is determined endogenously by free entry while the distribution of skills is fixed. In a standard assignment problem, the distributions on both sides of the market are fixed. The non-standard element in this paper simplifies the analysis and is important for the decentralizing mechanism, but it is not the reason why the efficient assignment can be non-positive. To the contrary, free entry of machines may even increase the chance for the efficient assignment to be positive, as the social planner can choose the distribution of machine qualities to alleviate the matching difficulty that high-skill workers face. In this sense, allowing for free entry on one side of the market makes it more striking that the efficient assignment can be non-positive.

\section{An Economy with Matching Frictions}

Consider an economy where all agents are risk neutral, live forever and have a discount factor $\beta \in(0,1)$. Workers differ in skills and, to make things simple, skills are observable and measurable by a one-dimensional object $s$ (e.g., education attainment), which lies in a set $S$ of discrete points with a minimum $s_{L}>0$ and a maximum $s_{H}$. There are a large, exogenous number of workers of each skill $s, n(s)$. Machines differ in qualities, denoted $k \in R_{+}$, and the distribution of machines is endogenously determined through firms' entry. At the end of the period, a machine vanishes with probability $\rho \in(0,1)$, which can be interpreted as the depreciation rate. A quality $k$ machine costs $C(k) /[1-\beta(1-\rho)]$ to make.

A worker can operate only one machine at a time. A skill $s$ worker and a quality $k$ machine together produce output $F(k, s)$. Utility is transferrable between firms and workers. ${ }^{4}$ The pair $(k, s)$ generates a surplus $F(k, s)-C(k)$ per period.

Assumption 1. (Regularity) (i) $C(0) \geq 0, C_{k}(0)=0, C_{k}(k)>0$ and $C_{k k}(k) \geq 0$ for all $k>0$; (ii) $F_{k}(k, s)>0, F_{k k}(k, s)<0, F_{s}(k, s)>0$ and $F_{s s}(k, s)<0$ for all $s$ and $k$;

\footnotetext{
${ }^{4}$ For a random matching environment with non-transferrable utility, see Burdett and Wright (1998).
} 
(iii) $F_{k s}>0, F(0, s)=F(k, 0)=0$;

(iv) There exists a non-empty subset $K \subset R_{+}$such that $F\left(k, s_{L}\right)-C(k)>0$ for all $k \in K$.

Conditions (i) and (ii) are standard. Condition (iii) requires skills and machine qualities to be complementary with each other and, for unmatched machines and workers, output to be zero. Condition (iv) says that even the lowest skill can produce positive net output with some machine qualities. Since $F_{s}>0$, there are machines that produce positive net output for all skill levels.

As in the search labor literature (e.g., Diamond 1982, Mortensen 1982, and Pissarides 1990), I adopt the following standard assumptions: (a) There is no coordination among workers or firms; (b) In each period a worker can have a match with only a limited number of firms, which I normalize to one, and mixed strategies are permitted; (c) Before making a machine available for matching, a firm must incur a vacancy cost, which I set to be the rental cost of the machine in the period; and (d) Only unemployed workers and vacant machines participate in the matching process. ${ }^{5}$ The assumptions (a) and (b) are important, because they imply matching frictions.

Matched workers produce immediately. Then, some pairs separate and join the matching pool next period. Each match with a skill $s$ worker separates with an exogenous probability $\sigma(s) \in(0,1)$, with a realistic restriction $\sigma^{\prime}(s) \leq 0 .{ }^{6}$ Part of the reason for separation is that the machine vanishes, and so $\sigma$ has already included the depreciation probability $\rho$.

The matching rates depend on the assignment between machines and workers. In principle, each machine can be assigned to match with multiple skills, with only one worker being chosen after the match. For such multiple-skill assignments, I exclude lexicographic selection rules by the following assumption.

Assumption 2. (Not-lexicographic) Take any $k \in K$. Suppose that a machine of quality $k$ is assigned to match with skills in a set $\left(s_{i}\right)_{i \in I}$, where $I$ is an index set and $s_{i} \in S$ for each $i$. Let $R_{i}$ be the number of $s_{i}$ workers received by the machine and $x_{i}$ the probability that the job is given to skill $s_{i}$. Assume $x_{i}>0$ for all $i \in I$ such that $R_{i}>0$.

This is a weak assumption, in the sense that it still permits the assignment to rank probabilistically the skills targeted to each machine. For example, if the assignment targets both skills $s_{1}$ and $s_{2}$ to a machine, it can give skill $s_{1}$ a higher selection probability than skill $s_{2}$. What the assumption does exclude in this case is that the assignment gives the job to skill $s_{1}$ with probability one even when both skills show up.

\footnotetext{
${ }^{5}$ If matched firms and workers could search, their incentives and options would be different from those who are unmatched. The resulting equilibrium would have a distribution of machine assignments and a distribution of wages for each skill.

${ }^{6}$ I assume that production immediately follows matching in the same period, rather than the typical assumption that new matches begin to produce in the next period. This difference in assumptions is inconsequential, but the current assumption makes it easy to interpret the results in the special case $\beta \rightarrow 0$ or $\sigma \rightarrow 1$ as the ones in a static model.
} 
Under Assumption Not-lexicographic, I will show in section 5 that there is no mixed matching at the level of individual machines; i.e., the efficient allocation assigns each machine to only one skill level. However, this does not preclude mixed matching at the aggregate level a priori. Machines of the same quality may be divided into different subgroups, with each subgroup being assigned to match with a distinct skill. Whether such aggregate mixing is socially efficient or consistent with an equilibrium is an issue that will be examined in this paper.

Because each machine is assigned to only one skill level, let me pick a particular skill level $s \in S$ and describe the machines assigned to the workers of such skill in a period. Let $\phi(s)$ denote the set of machine qualities that are assigned to match with skill $s$ workers and $\phi^{-1}(k)$ the set of skill levels that are assigned to match with quality $k$ machines. For each $k \in \phi(s)$, let $M(k, s)$ be the number of quality $k$ machines and $M(k, s) B(k, s)(\leq n(s))$ the number of unemployed skill $s$ workers assigned to match with each other. Call this subgroup of machines and unemployed workers the unit $(k, s)$. The number $B$ is the tightness of workers in the unit, where a higher $B$ means higher congestion of workers. The matching rates in the unit are as follows:

$$
\begin{array}{ll}
\text { for each machine: } & 1-e^{-B(k, s)} \\
\text { for each worker: } & \mu(k, s) \equiv\left[1-e^{-B(k, s)}\right] / B(k, s) .
\end{array}
$$

These matching rates will be derived later from the decentralized economy in section 4 . The planner is constrained by these matching rates.

An assignment in period $t$ is a set of machine qualities $\phi_{t}(s)$ for each $s \in S$ and the two numbers $\left(M_{t}\left(k_{t}, s\right), B_{t}\left(k_{t}, s\right)\right)$ for each $k_{t} \in \phi_{t}(s)$. The numbers $M$ and $B$ are a necessary part of an assignment, in addition to $\phi$, because they determine the number of matches which is important for social welfare. However, I will often follow the convention to refer to $\phi$ as the assignment. The assignment is one-to-one if both $\phi$ and $\phi^{-1}$ are single-valued. Otherwise, the assignment is mixed at the aggregate level. The assignment is positive if $\phi$ is monotone.

Before characterizing the efficient assignment in the frictional environment, let me characterize the assignment without the matching friction. In such a frictionless world, all workers are matched instantaneously. The planner picks machine qualities $\phi^{p}(s)$ for skill $s$ workers to maximize the social surplus for each pair. That is, for each $s \in S$, the frictionless assignment $\phi^{p}(s)$ is such that

$$
F_{k}\left(k^{p}(s), s\right)=C_{k}\left(k^{p}(s)\right) \text { for all } k^{p}(s) \in \phi^{p}(s) .
$$

Under Assumption Regularity, $\phi^{p}(s)$ is a singleton. It is also positive and time-invariant. With free entry of firms, the competitive equilibrium that decentralizes this frictionless assignment exhausts all profits. So, the frictionless wage rate of skill $s$ workers is

$$
w^{p}(s)=F\left(\phi^{p}(s), s\right)-C\left(\phi^{p}(s)\right) .
$$




\section{Efficient Assignment with Frictions}

\subsection{Formulation and definition}

Constrained by matching frictions, the social planner chooses $(\phi, M, B)$ to maximize the discounted sum of match surpluses. The calculation of these surpluses is complicated, due to the irreversibility of machine costs. The following conjecture simplifies the calculation and it will be verified later in Proposition Stable:

Conjecture 3.1. For any $k$ and any $t \geq 0$, the number of quality $k$ machines demanded in the matching process in period $t+1$ is greater than or equal to the number of such machines that are vacant at the end of period $t$ after separation and depreciation.

Under this conjecture, a machine will be used in every period since its creation, in either production or the matching process, until it vanishes. Instead of counting the total cost of the machine at the time of its creation, I can equivalently count the present value of the rents accrued to the machine. The proper discount factor in calculating the present value of rents is $\beta(1-\rho)$.

Now consider a machine in the unit $\left(k_{t}, s\right)$. The vacancy cost in period $t$ is $C\left(k_{t}\right)$. If the machine is matched in the period, the flow of net output is $\left[F\left(k_{t}, s\right)-C\left(k_{t}\right)\right]$ in each future period where the machine remains matched. ${ }^{7}$ The discount factor on future net output is $a(s) \equiv$ $\beta[1-\sigma(s)]$, which takes future separation into account. The present value of net output created by the match, not accounting the vacancy cost in the current period, is

$$
\begin{aligned}
P V\left(k_{t}, s\right) & =F\left(k_{t}, s\right)+\sum_{\tau=t+1}^{\infty}[a(s)]^{\tau-t}\left[F\left(k_{t}, s\right)-C\left(k_{t}\right)\right] \\
& =\left[F\left(k_{t}, s\right)-a(s) C\left(k_{t}\right)\right] /[1-a(s)] .
\end{aligned}
$$

Because each machine in the unit $\left(k_{t}, s\right)$ is matched with probability $1-e^{-B_{t}\left(k_{t}, s\right)}$ and there are $M_{t}\left(k_{t}, s\right)$ such machines in the unit, the expected social surplus generated in this unit is

$$
E V\left(k_{t}, s\right) \equiv M_{t}\left(k_{t}, s\right)\left\{\left[1-e^{-B_{t}\left(k_{t}, s\right)}\right] P V\left(k_{t}, s\right)-C\left(k_{t}\right)\right\}
$$

The efficient assignment maximizes the discounted sum of $E V\left(k_{t}, s\right)$, summing over skills, machine qualities, and time.

The assignment in a period affects the number of workers available for future matches. Let $u_{t}(s)$ be the number of skill $s$ workers who are unemployed at the beginning of $t$, and $E_{t}(s)$ the number of skill $s$ workers who are employed in period $t$ before separation takes place. Then,

$$
\begin{gathered}
u_{t}(s)=n(s)-[1-\sigma(s)] E_{t-1}(s) \\
E_{t}(s)=[1-\sigma(s)] E_{t-1}(s)+\sum_{k_{t} \in \phi_{t}(s)} M_{t}\left(k_{t}, s\right)\left[1-e^{-B_{t}\left(k_{t}, s\right)}\right] .
\end{gathered}
$$

\footnotetext{
${ }^{7}$ Notice that the machine quality $k_{t}$ does not change over time for the pair, since there is no re-assignment for the pair as long as they stay matched.
} 
Eq. (3.3) is an accounting identity. Eq. (3.4) states that employment in period $t$ consists of employed workers in period $t-1$ who did not separated and the workers newly recruited in period $t$. Combining the two equations yields the following law of motion of $u$ :

$$
u_{t+1}(s)=\sigma(s) n(s)+[1-\sigma(s)]\left\{u_{t}(s)-\sum_{k_{t} \in \phi_{t}(s)} M_{t}\left(k_{t}, s\right)\left[1-e^{-B_{t}\left(k_{t}, s\right)}\right]\right\} .
$$

Clearly, the number of unemployed skill $s$ workers allocated for matching across different units cannot exceed the available number $u_{t}(s)$, and so the following inequality must hold:

$$
\sum_{k_{t} \in \phi_{t}(s)} M_{t}\left(k_{t}, s\right) B_{t}\left(k_{t}, s\right) \leq u_{t}(s)
$$

Let $\lambda_{t}(s) /[1-\sigma(s)]$ be the multiplier of the constraint (3.5), measured in terms of period- $t$ utility. As it will become clear later, $\lambda$ is the (discounted) future value of workers. For the efficient allocation to have non-trivial solution, $\lambda$ must satisfy the transversality condition, as stated in the following definition.

Definition 3.2. An efficient allocation is a triple $\left(\phi^{o}, M^{o}, B^{o}\right)$ which solves:

$$
\left(P^{o}\right) \quad \max \sum_{t=0}^{\infty} \beta^{t} \sum_{s \in S} \sum_{k_{t} \in \phi_{t}(s)} E V\left(k_{t}, s\right)
$$

for a given initial distribution $\left\{u_{0}(s)\right\}_{s \in S}$ (i.e., for $\left.\left\{E_{-1}(s)\right\}_{s \in S}\right)$, subject to (3.5), (3.6), and the following transversality condition:

$$
\lim _{t \rightarrow \infty} \beta^{t} \lambda_{t}(s)=0, \text { for all } s \in S .
$$

\subsection{Recursive formulation and the solution}

For an assignment to be efficient, it must make the best trade-off between current and future matches. To highlight this intertemporal trade-off, it is useful to reformulate the allocation problem recursively. Pick an arbitrary period $t$ and suppress the subscript $t$ whenever possible. Use the subscript $+i$ to stand for $t+i$ and $-i$ for $t-i$. Let $L(u(s))$ be the total social value of skill $s$ workers unemployed at the beginning of the period. Then,

$$
\left(P^{\prime}\right) \quad L(u(s))=\max _{(\phi, M, B)}\left[\sum_{k \in \phi(s)} E V(k, s)+\beta L\left(u_{+1}(s)\right)\right] \text { s.t. (3.5) and (3.6). }
$$

It is easy to verify that for each $s \in S$, the solution to $\left(P^{\prime}\right)$ is the same as to $\left(P^{o}\right)$. Note that $\lambda(s)=a(s) L^{\prime}\left(u_{+1}(s)\right)$ (recall that $a \equiv \beta(1-\sigma)$ ), and so $\lambda(s)$ is indeed the social marginal value of (unemployed) skill $s$ workers in the next period. ${ }^{8}$ Refer to the multiplier of $(3.6)$ in $\left(P^{\prime}\right)$ as the social gain from matching a skill $s$ worker today relative to tomorrow and denote it as $\Omega(s)$.

\footnotetext{
${ }^{8}$ The discounting takes into account the fact that separation in the current period increases the number of unemployed workers in the future and hence deflates the social value of such workers.
} 
The recursive formulation indicates that the current assignment depends on future assignments only through $\lambda$. Given $\lambda$, I can decompose the infinite horizon problem into a sequence of oneperiod problems. In turn, the path of $\lambda$ can be determined by requiring it to be consistent with rational expectations (i.e., perfect foresight). For any given future value of workers, $\lambda(s)$, the assignment problem in a period is as follows:

$$
\left(P^{\prime \prime}\right) \max _{(k, B)} e^{-B(k, s)}[P V(k, s)-\lambda(s)]
$$

subject to:

$$
1-[1+B(k, s)] e^{-B(k, s)}=\frac{C(k)}{P V(k, s)-\lambda(s)} .
$$

Lemma 3.3. (Decompose) For any given $\lambda(s)$, let $k^{I}(s)$ and $B^{I}\left(k^{I}(s), s\right)$ solve $\left(P^{\prime \prime}\right)$. If $\lambda$ obeys (3.8) and

$$
\lambda_{-1}(s)=a(s)\left\{\lambda(s)+e^{-B^{o}\left(k^{o}, s\right)}\left[P V\left(k^{o}, s\right)-\lambda(s)\right]\right\}
$$

then $k^{I}(s)=k^{o}(s) \in \phi^{o}(s)$ and $B^{I}=B^{o}$.

Proof. I first characterize the solution to $\left(P^{\prime}\right)$. Since $k^{o} \in \phi^{o}(s)$, I have $M^{o}\left(k^{o}, s\right)>0$ and $B^{o}\left(k^{o}, s\right)>0$. Suppress the superscript $o$. Noting that $\lambda(s) /[1-\sigma(s)]$ is the multiplier of (3.5) and $\Omega(s)$ of (3.6), I can obtain the following first-order conditions of $\left(P^{\prime}\right)$ for $(k, M, B)$ and the envelope condition for $u$ :

$$
\begin{gathered}
{\left[1-e^{-B(k, s)}\right] P V_{k}(k, s)=C_{k}(k),} \\
{\left[1-e^{-B(k, s)}\right][P V(k, s)-\lambda(s)]-C(k)=\Omega(s) B(k, s),} \\
\Omega(s)=e^{-B(k, s)}[P V(k, s)-\lambda(s)], \\
\lambda_{-1}(s)=a(s)[\lambda(s)+\Omega(s)] .
\end{gathered}
$$

In addition, the transversality condition (3.8) must be satisfied. Using (3.13) to eliminate $\Omega$, (3.12) becomes (3.9) and (3.14) becomes (3.10). That is, if the sequence of $\lambda(s)$ obeys (3.8) and (3.10), then (3.9) and (3.11) characterize the efficient $k^{o}(s) \in \phi^{o}(s)$ and $B^{o}\left(k^{o}(s), s\right)$. To prove the lemma, it suffices to show that the first order condition of $\left(P^{\prime \prime}\right)$ for $k$ produces (3.11). This is straightforward.

QED

The problem $\left(P^{\prime \prime}\right)$ in Lemma Decompose admits a simple interpretation. It states that, in each period and for each skill, the efficient machine quality and the tightness maximize the social gain from matching a worker, subject to a zero net-profit condition for each machine.

The objective function in $\left(P^{\prime \prime}\right)$ is the social gain from matching a skill $s$ worker today rather than tomorrow, as (3.13) indicates. To explain why it is so, suppose that an additional skill $s$ worker is available for matching in the current period. Allocating this worker to a machine increases the social value only when the machine has failed to match in the current period, which 
occurs with probability $e^{-B}$. In this event, the match generates a present value $P V(k, s)$. At the same time, it destroys the opportunity value of delaying the worker for matching in the next period, the discounted value of which is $\lambda(s)$. Thus, the net gain from the additional worker is $e^{-B}[P V(k, s)-\lambda(s)]=\Omega(s)$.

The constraint for $\left(P^{\prime \prime}\right),(3.9)$, requires net profit of (or the social net gain from) a machine $k$ to be zero, which is necessary for the number of machines to be efficient. To see this, consider adding a quality $k$ machine to the matching process in the current period, where $k \in \phi(s)$. This additional machine gets a match with probability $1-e^{-B}$. However, it also reduces the relative number of workers to machines in the matching process, and hence crowds out the number of matches for existing machines, by $M \frac{\partial}{\partial M}\left(1-e^{-B}\right)=-B e^{-B}$. Thus, the social contribution of this additional machine is $\left(1-e^{-B}-B e^{-B}\right)(P V-\lambda)$. Eq. (3.9) requires this social contribution to be equal to the cost of the machine in the current period.

For given $\lambda$ and $s$, Figure 1 illustrates the solution to $\left(P^{\prime \prime}\right)$. The curve $B=I N D(k)$ depicts the combinations of $(k, B)$ that generate the same level of social net gain from matching with a skill $s$ workers today. This is an upward-sloping curve because when the machine quality increases, congestion must be higher on the workers' side in order to keep the workers' social value constant. The curve $I N D(k)$ is also concave. ${ }^{9}$ The curve $B=Z N P(k)$ depicts the zero net profit condition (3.9). It is upward-sloping because a higher quality machine is more costly to make, which requires a higher matching rate in order to break even. The efficient assignment is given by point $E$, where the two curves are tangent to each other.

Figure 1 here.

For the solution to be unique, the curve $I N D(k)$ must be more concave than $Z N P(k)$ whenever the two are tangent to each other, i.e., $Z N P_{k k}>I N D_{k k}$ whenever $Z N P_{k}=I N D_{k}$. The following proposition specifies this condition more explicitly and states the existence result (see Appendix A for a proof).

Proposition 3.4. (Existence) Assume $\lambda(s) \in(0, \bar{\lambda}(s)]$ for some $\bar{\lambda}(s)>0$. If

$$
F_{k} C_{k k}-C_{k} F_{k k}>\frac{\left(F_{k}-C_{k}\right)\left[F_{k}-a(s) C_{k}\right]^{2}}{[1-a(s)][F-a(s) C-(1-a(s)) \bar{\lambda}(s)]} .
$$

then $\left(P^{\prime \prime}\right)$ has a unique solution. That is, $\phi^{\circ}(s)$ exists and is a singleton for each $s$. Moreover, $k_{\min }(s)<\phi^{o}(s)<k_{\max }(s)$ for every $s \in S$, where $k_{\max }(s)$ and $k_{\min }(s)$ are defined as follows:

$$
\begin{gathered}
{\left[F_{k}(k, s)-C_{k}(k)\right]_{k=k_{\max }(s)}=0,} \\
{\left[F(k, s) C_{k}(k)-C(k) F_{k}(k, s)\right]_{k=k_{\min }(s)}=0 .}
\end{gathered}
$$

\footnotetext{
${ }^{9}$ This can be verified using $I N D(k)=\ln [P V(k, s)-\lambda(s)]-\ln \Omega(s)$.
} 
Because a unique machine quality is assigned to each skill, mixed matching at the aggregate level is not efficient. Thus, I will use $\phi^{o}(s)$ to refer to the level, rather than the set, of machine quality assigned to skill $s$. Then, $b^{o}(s) \equiv B^{o}\left(\phi^{o}(s), s\right)$ is the efficient tightness for skill $s$ in the period and $m^{o}(s) \equiv u(s) / b^{o}(s)$ is the efficient number of new machines $\phi^{o}(s)$ assigned to skill $s$ workers. The numbers $b^{o}$ and $\phi^{o}$ must satisfy the first-order condition (3.11) and the constraint (3.9) of $\left(P^{\prime \prime}\right)$, which can be rewritten as follows:

$$
\begin{gathered}
1-e^{-b^{o}(s)}=\frac{[1-a(s)] C_{k}\left(\phi^{o}(s)\right)}{F_{k}\left(\phi^{o}(s), s\right)-a(s) C_{k}\left(\phi^{o}(s)\right)} ; \\
1-\left[1+b^{o}(s)\right] e^{-b^{o}(s)}=\frac{C\left(\phi^{o}(s)\right)}{P V\left(\phi^{o}(s), s\right)-\lambda(s)} .
\end{gathered}
$$

Solve $b^{o}$ from (3.18) as a function of $\phi^{o}$. Denote this solution as $b^{o}=b\left(\phi^{o}\right)$, where the dependence on $s$ is suppressed. Substituting this function into (3.19), I can solve $\phi^{o}$. Denote this solution as $\phi^{o}=\phi(\lambda)$ to emphasize its dependence on the future value of workers.

\subsection{The intertemporal link and dynamic stability}

Proposition Existence has established existence and uniqueness of the efficient assignment for any given sequence $\left\{\lambda_{t}\right\}_{t \geq 0}$. To characterize the efficient assignment completely, I must determine the $\lambda$ sequence by resorting to the analysis of dynamic stability. Because the assignment in the current period depends on future assignments only through the future value of workers, $\lambda$, it is important to analyze first how $\lambda$ affects the current assignment. Suppressing the skill index $s, \mathrm{I}$ summarize such effects by the following lemma: ${ }^{10}$

Lemma 3.5. (Intertemporal-link) An increase in $\lambda$ reduces the social net gain from a current worker, $\Omega$, and increases $b^{\circ}$ and $\phi^{\circ}$. That is, $b^{\prime}(\phi)>0, \phi^{\prime}(\lambda)>0$ and $d \Omega / d \lambda<0$.

An increase in the future value of workers increases the machine quality and the market tightness assigned to current workers. This is intuitive. When the future value of workers increases, the net gain from a current worker $(\Omega)$ falls. In this case, it is socially desirable to reduce the number of current matches and increase the number of future matches. The only way to do so is to reduce the number of machines in the current period, i.e., to increase the tightness for workers. However, reducing the number of machines increases the matching probability for each machine and hence increases the social net gain from each machine. To maintain zero social net gain from the machines, the cost of machines must rise, which entails an increase in the machine quality.

Figure 1 shows the effects of $\lambda$. When $\lambda$ increases, the social net gain generated by a machine today, relative to tomorrow, falls; for a machine to make a zero net profit, its utilization rate must rise, which requires an increase in $B$. So, the $Z N P(k)$ curve shifts up, say, to $Z N P^{\text {new }}(k)$.

\footnotetext{
${ }^{10}$ The proof, omitted here, involves straightforward differentiation of (3.18), (3.19), and (3.13) with respect to $\lambda$.
} 
Similarly, an increase in $\lambda$ reduces the social net gain from matching a worker today relative to tomorrow; to keep such a social net gain constant, the worker must get a match at a higher rate, which requires a decrease in $B$. That is, the entire map of $I N D(k)$ curves shifts down for any given $\Omega$. Notice that neither the $Z N P$ curve nor the $I N D$ curve shifts in a parallel fashion. Rather, the lower the level of $k$, the larger the shift, because of the complementarity between skills and machine qualities. If a worker is matched with a low machine quality, his matching rate must increase by a large amount in order to generate the same net social gain as before the increase in $\lambda$. In the new map of $I N D$ curves, one of them is tangent to $Z N P^{n e w}(k)$. This is labelled $I N D^{\text {new }}(k)$ in Figure 1, which corresponds to a lower $\Omega$ than the original $I N D$ curve. The new assignment is depicted by point $E^{\prime}$.

Next, I reduce the dimension of the dynamic system. Substitute the functions $b(\phi)$ and $\phi(\lambda)$ into (3.10) to obtain:

$$
\lambda_{-1}=\Psi(\lambda) \equiv a\left\{\lambda+e^{-b(\phi(\lambda))}[P V(\phi(\lambda))-\lambda]\right\}
$$

Let $r u \equiv u / n$ be the unemployment rate of the workers of the particular skill. Then (3.5) becomes:

$$
r u_{+1}=\sigma+(1-\sigma)\left[1-\frac{1-e^{-b(\phi(\lambda))}}{b(\phi(\lambda))}\right] r u .
$$

Eqs. (3.20) and (3.21) form a dynamic system for $\left(\lambda_{-1}, r u\right)$, where $\lambda_{-1}$ is a jump variable and $r u$ is a state variable with an initial value $r u_{0} \in(0,1)$.

The following proposition states existence, uniqueness, and local stability of the steady state, indicated by a superscript $*$ (see Appendix B for a proof):

Proposition 3.6. (Stable) The equilibrium has a unique, saddle-path stable steady state. Along the saddle path, $\left(\lambda_{t-1}, b_{t}, \phi_{t}\right)=\left(\lambda^{*}, b^{*}, \phi^{*}\right) \forall t \geq 0$, while the sequence $\left\{r u_{t}\right\}_{t \geq 0}$ approaches the steady state monotonically. Moreover, Conjecture 3.1 is satisfied around the steady state.

The social value of workers, $\lambda$, is constant over time along the entire dynamic path! This implies that $b$ and $\phi$ are also constant over time for each skill.

The constant time-path of $\lambda$ is a result of the intertemporal trade-off. To explain, suppose $\lambda_{-1}>\lambda^{*}$; i.e., the value of workers in the current period exceeds the steady state value. In this case, it is costly to delay a match to next period. The costs include time discounting and the net gain $\Omega$ from a current match. For it to be efficient to leave some workers for future matches, the future value of workers $(\lambda)$ must exceed the steady state value $\lambda^{*}$ sufficiently to compensate for these costs. More precisely, $\left(\lambda-\lambda^{*}\right)$ must exceed $\left(\lambda_{-1}-\lambda^{*}\right)$ by more than $1 / a$. However, this violates the transversality condition, as the assignment delays too many workers to distant future matches. By re-allocating some of these workers to current matches, social welfare increases. Similarly, the situation $\lambda_{-1}<\lambda^{*}$ is inconsistent with intertemporal efficiency. 
Another way to phrase the above explanation is to calculate the implicit rate of return to matches. The implicit return is $(\Omega+\lambda)$ and the rate of return $(\Omega+\lambda) / \lambda_{-1}$. The efficient allocation requires that this rate of return be equal to the effective discount rate $1 / a$ (see (3.20)). For any given current value of workers, $\lambda_{-1}$, an increase in $\lambda$ reduces $\Omega$ (see Lemma Intertemporal-link) and hence increases the return by less than one for one. If $\lambda_{-1}>\lambda^{*}$, then $\left(\lambda-\lambda^{*}\right)$ must exceed $\left(\lambda_{-1}-\lambda^{*}\right)$ by more than $1 / a$ in order to satisfy the efficiency requirement on the rate of return. This violates the transversality condition.

Since $(\lambda, \phi, b)$ are constant over time, I suppress the time subscript on these variables and the superscript $*$ on the steady state. Substituting $\lambda^{*}$ from (3.20), I can rewrite the condition for existence and uniqueness of the assignment, (3.15), as follows:

$$
\frac{F_{k} C_{k k}-C_{k} F_{k k}}{F_{k}-C_{k}}>\frac{\left(F_{k}-a C_{k}\right)\left[F_{k}-a(2-a) C_{k}\right]}{(1-a)^{2}(F-a C)} .
$$

Similarly, the conditions that characterize the efficient assignment, (3.18) and (3.19), become

$$
\begin{gathered}
F_{k} / C_{k}=1+\frac{1-a}{e^{b}-1} ; \\
F / C=1+\frac{1+(1-a) b}{e^{b}-1-b},
\end{gathered}
$$

where $C=C(\phi(s)), F=F(\phi(s), s)$, and the superscript $o$ is suppressed.

\subsection{Properties of the efficient assignment}

With the above stability results, the properties of the assignment become very similar to those in the one-period setup examined in Shi (2001). In this subsection, I briefly state these properties for the special case $\sigma(s)=\sigma \cdot{ }^{11}$ The proofs are omitted, as they involve only comparative statics using (3.23) and (3.24).

Proposition 3.7. (Property) The assignment $\phi$ is positive, i.e., $\phi^{\prime}(s)>0$, if and only if

$$
F_{k s}>\frac{C F_{s}\left(F_{k}-C_{k}\right)\left(F_{k}-a C_{k}\right)\left[F_{k}-a(2-a) C_{k}\right]}{(1-a)^{2}(F-a C) C_{k}\left(F C_{k}-C F_{k}\right)} .
$$

A higher skill has a higher matching rate, i.e., $b^{\prime}(s)<0$, if and only if

$$
F_{k s}<\frac{C F_{s}\left(F_{k} C_{k k}-C_{k} F_{k k}\right)}{C_{k}\left(F C_{k}-C F_{k}\right)}
$$

Thus, $b^{\prime}(s) \geq 0$ implies $\phi^{\prime}(s)>0$, and $\phi^{\prime}(s) \leq 0$ implies $b^{\prime}(s)<0$. Under (v) in Assumption Regularity, there is a non-empty parameter region in which both $\phi^{\prime}(s)>0$ and $b^{\prime}(s)<0$.

\footnotetext{
${ }^{11}$ By continuity, the same properties will hold if $\sigma(s)$ does not decrease significantly in $s$.
} 
For the efficient machine assignment to be positively assortative, skills and machine qualities must be sufficiently complementary with each other. To understand this result, consider the case $F_{k s} \approx 0$, in which (3.25) is violated. Since high-quality machines are costly to make, the utilization rates of high-quality machines and high-skill workers are low if the assignment is positive. If, instead, the planner assigns high-skill workers to match with medium- or low-quality machines and high-quality machines to match with medium- or low-skill workers, the utilization rates of both high-quality machines and high-skill workers will increase significantly. Since machine qualities and skills are barely complementary with each other in this case, the efficiency gain from the increase in utilization outweighs the loss of productivity from the non-positive assignment. So, expected social surplus will increase.

The efficient assignment also implies socially efficient compensations for workers, or the efficient wage rates. Let $w^{o}(s)$ denote the efficient wage rate for skill $s$ workers. The present value of expected efficient wages must be equal to the social net gain from matching a worker. Thus, $\Omega=\mu w^{o}+(1-\mu) a \Omega_{+1}$, where $\mu=\left(1-e^{-b}\right) / b$ is the worker's matching probability. Since $\Omega_{+1}=\Omega$ along the stable path, $w^{o}=\Omega[1-(1-\mu) a] / \mu$. Calculating $\Omega=e^{-b}(P V-\lambda)$, substituting $F$ with (3.24) and suppressing the superscript $o$, I have:

$$
w=\frac{C(\phi)}{e^{b}-1-b}\left[a+\frac{1-a}{\mu}\right] .
$$

Proposition 3.8. (Social-value) The social gain from matching a worker today relative to tomorrow, $\Omega(s)$, and the social value of workers, $\lambda(s)$, are increasing functions of the skill, regardless of the signs of $\phi^{\prime}(s)$ and $b^{\prime}(s)$. If $\phi^{\prime}(s) \geq 0$, then $w^{\prime}(s)>0$. Moreover, $w^{\prime}(s)<F_{s}(\phi(s), s)$ if and only if $b^{\prime}(s)<0$.

The social gain from matching a worker and the social value of workers always increase with the skill level, even when the assignment is non-positive. This is intuitive because high skills are more productive resources than low skills. If a non-positive assignment is called for, it is to increase utilization of highly productive resources. Such an assignment could not be efficient if high-skill workers yielded lower social values than low-skill workers.

However, the actual wage rate does not necessarily increase with the skill level, especially when the assignment is non-positive. When a high skill is assigned to a machine with a very low quality, the actual output per period is low, which implies a low actual wage. This outcome does not violate the efficiency requirement $\lambda^{\prime}(s)>0$ or $\Omega^{\prime}(s)>0$ because the high skill is utilized with a much higher probability than a low skill.

Proposition Social-value also states that the marginal reward to skill, $w^{\prime}(s)$, is less than the marginal product of skill if and only if the matching rate increases with skill. If the wage rate over-compensates for a skill's marginal product, it must be the case that the skill is matched at a low rate. If the wage rate compensates for the skill's marginal product deficiently, then the skill 
must be compensated additionally by a higher matching rate. When the compensation through an increased matching probability is sufficient, the wage can even fall with skill.

\section{Decentralization}

To decentralize the efficient assignment, consider a competitive economy with the following features. Machine makers produce machines and rent them to firms at the competitive market rate. Each quality $k$ machine is rented for $C(k)$ per period. In each period, the firms and workers take the following sequence of actions:

(i) The firms can target any machine quality to unemployed workers of a particular skill. When contemplating a machine quality $k_{t}$ for a skill $s$, a firm expects to face a market tightness, $B_{t}\left(k_{t}, s\right)$, which is determined by a zero-profit condition for entry. That is, the firm anticipates that many other firms can make the same pairing to drive net expect profit to zero.

(ii) Taking the tightness schedule as given, the firms select machine qualities $\phi_{t}(s)$ for each skill $s$ and choose a wage path $\left\{W_{\tau}\left(k_{t}, s\right)\right\}_{\tau \geq t}$ for $k_{t} \in \phi_{t}(s)$. Then all firms simultaneously announce the skills they target the machines to and the corresponding wages. The firms must commit to hiring these skills and paying these wages. As before, the selection rule cannot be lexicographic. This implies that the firms will target each machine to only one skill level in equilibrium, as shown in section 5 .

(iii) Observing the firms' announcements, unemployed workers decide which firm to apply to, possibly with mixed strategies. ${ }^{12}$ If a firm receives applicants of the skill it committed to, it randomly chooses one. The pair produces and the worker is paid according to the posted wage path until the pair separates. If a firm fails to recruit any worker of the desired skill, output is zero in the current period. In the event of a match failure or separation, the firm can return the machine (if undepreciated) to the owner and choose a machine optimally next period.

I solve this equilibrium assignment problem in each period backward. Although a firm announces the machine quality and wage rates simultaneously, it is convenient to analyze the choice of wages first for any given choice of machine quality $k$, as I will do below.

\subsection{Wages for newly recruited skill $s$ workers}

Given the firms' choices of machines and commitments to particular skills, consider the recruiting game in period $t$. Since the firms with machines other than $\phi_{t}(s)$ commit to not hiring skill $s$, unemployed skill $s$ workers, and only those workers, apply to vacancies with machines $\phi_{t}(s)$. For the recruiting game in period $t$, I can then isolate skill $s$ workers and the machines of a quality $k_{t} \in \phi_{t}(s)$. Let $M_{t}\left(k_{t}, s\right)$ be the number of machines $k_{t} \in \phi_{t}(s)$ chosen for skill $s$. I suppress the

\footnotetext{
${ }^{12}$ The qualitative results will be similar if each worker observes only two independently drawn announcements in each group of firms, but the exercise is more cumbersome (see Acemoglu and Shimer 1999).
} 
index $s$ in this subsection, referring to an unemployed skill $s$ worker as an unemployed worker and to a new machine $k_{t}$ in the group $\phi_{t}(s)$ as a machine $k_{t}$.

I will first analyze skill $s$ workers' application decisions and then the firms' wage decisions. Focus on the symmetric equilibrium where all unemployed workers of the same skill use the same strategy and all recruiting firms that choose the same machine quality for the same skill use the same strategy. This focus is justified by the focus on the limit economy with large numbers $u_{t}(s)$ and $M_{t}\left(k_{t}, s\right)$ (but with a finite ratio $u_{t}(s) / M_{t}\left(k_{t}, s\right)$ ), where it is difficult for agents to coordinate on asymmetric equilibria, including pure-strategy equilibria. ${ }^{13}$

Let me compute the matching rates in equilibrium. Denote $p\left(k_{t}\right)$ as the probability with which an unemployed worker applies to a firm with machine $k_{t}$. Denote the equilibrium tightness for each machine $k_{t}$ by

$$
B_{t}\left(k_{t}\right) \equiv \lim u_{t} p\left(k_{t}\right)
$$

where the limit is taken over $u_{t} \rightarrow \infty$ with $M_{t}\left(k_{t}\right) / u_{t} \in(0, \infty)$. Each recruiting firm with a machine $k_{t}$ fills the vacancy in period $t$ with probability

$$
1-\left[1-p\left(k_{t}\right)\right]^{u_{t}} \rightarrow 1-e^{-B_{t}\left(k_{t}\right)}
$$

Similarly, each unemployed worker gets a job in period $t$ with a probability

$$
\frac{1-\left[1-p\left(k_{t}\right)\right]^{u_{t}}}{u_{t} p\left(k_{t}\right)} \rightarrow \frac{1-e^{-B_{t}\left(k_{t}\right)}}{B_{t}\left(k_{t}\right)} \equiv \mu_{t}\left(k_{t}\right) .
$$

These are the matching rates used in the social planner's problem.

Next, I compute equilibrium payoffs. Denote $A_{\tau}\left(k_{t}\right)=W_{\tau}\left(k_{t}\right) / F\left(k_{t}\right)$ as the wage share for period $\tau \geq t$ posted by a firm recruiting in period $t$ with machine $k_{t}$. For $T \geq t$, denote $\mathcal{A}_{T}\left(k_{t}\right) \equiv\left\{A_{\tau}\left(k_{t}\right)\right\}_{\tau \geq T}$. Let $J_{f T}\left(\mathcal{A}_{T}\left(k_{t}\right)\right)$ be the present value to a firm from period $T$ onward of a utilized machine $k_{t}$ that successfully recruited in period $t$ with a wage share path $\mathcal{A}_{t}\left(k_{t}\right)$. Let $J_{v T}\left(k_{t}\right)$ be the present value from period $T$ onward of a vacant machine $k_{t}$. Similarly, let $V_{e T}\left(\mathcal{A}_{T}\left(k_{t}\right)\right)$ be the present value from period $T$ onward to a worker who has been employed from period $t$ with a machine $k_{t}$ and a wage share path $\mathcal{A}_{t}\left(k_{t}\right)$, and $V_{u T}$ be the present value of an unemployed worker in period $T$. These value functions obey the following Bellman equations:

$$
\begin{gathered}
J_{f t}\left(\mathcal{A}_{t}\left(k_{t}\right)\right)=\left[1-A_{t}\left(k_{t}\right)\right] F\left(k_{t}\right)+\sigma \beta J_{v t+1}\left(k_{t+1}\right)+a\left[J_{f t+1}\left(\mathcal{A}_{t+1}\left(k_{t}\right)\right)-C\left(k_{t}\right)\right] \\
J_{v t}\left(k_{t}\right)=-C\left(k_{t}\right)+\left[1-e^{-B_{t}\left(k_{t}\right)}\right] J_{f t}\left(\mathcal{A}_{t}\left(k_{t}\right)\right)+e^{-B_{t}\left(k_{t}\right)} \beta J_{v t+1}\left(k_{t+1}\right) \\
V_{e t}\left(\mathcal{A}_{t}\left(k_{t}\right)\right)=A_{t}\left(k_{t}\right) F\left(k_{t}\right)+\sigma \beta V_{u t+1}+a V_{e t+1}\left(\mathcal{A}_{t+1}\left(k_{t}\right)\right)
\end{gathered}
$$

\footnotetext{
${ }^{13}$ Of course, I allow firms to use different strategies if they wish to target different machine qualities to the same skill or target the same machine quality to different skills. Similarly, workers of the same skill can use different strategies when applying to different machine qualities in the set $\phi_{t}(s)$. Moreover, firms that recruit in different periods do not have to use the same strategies even if they use the same machine quality to target the same skill.
} 


$$
V_{u t}=\mu_{t}\left(k_{t}\right) V_{e t}\left(\mathcal{A}_{t}\left(k_{t}\right)\right)+\left[1-\mu_{t}\left(k_{t}\right)\right] \beta V_{u t+1} .
$$

These equations are standard in search theory of unemployment. For example, (4.3) equates the present value of a vacancy to the expected value from hiring minus the vacancy cost $C$. With probability $1-e^{-B}$ the job is filled, in which case the job yields a present value $J_{f t}$. With probability $e^{-B}$ the vacancy remains unfilled in period $t$, in which case the firm can choose possibly a different machine to post a vacancy yielding a value $\beta J_{v t+1}\left(k_{t+1}\right)$. Note that, unlike $\left(J_{f}, V_{e}\right)$, the future values of $\left(J_{v}, V_{u}\right)$ do not depend on specific firms' wage offers.

Now consider a single recruiting firm in the unit $\left(k_{t}, s\right)$ that deviates to a different wage share path $\mathcal{A}_{t}^{d}\left(k_{t}\right) \equiv\left\{A_{\tau}^{d}\left(k_{t}\right)\right\}_{\tau \geq t}$, where the superscript $d$ indicates deviation. All other recruiting firms in the unit $\left(k_{t}, s\right)$ continue to post the share path $\mathcal{A}_{t}\left(k_{t}\right)$. If the deviating firm succeeds in hiring a worker in $t$, it pays wages according to the share path $A_{t}^{d}\left(k_{t}\right)$ until the job is separated. For the deviator, the present value of a filled job is $J_{f t}\left(\mathcal{A}_{t}^{d}\left(k_{t}\right)\right)$, computed in the same way as (4.2) by replacing $\mathcal{A}_{t}\left(k_{t}\right)$ with $\mathcal{A}_{t}^{d}\left(k_{t}\right)$. Then,

$$
J_{f t}\left(\mathcal{A}_{t}^{d}\left(k_{t}\right)\right)=\sum_{\tau=0}^{\infty} a^{\tau}\left\{\left[1-A_{t+\tau}^{d}\left(k_{t}\right)\right] F\left(k_{t}\right)-a C\left(k_{t}\right)+\sigma \beta J_{v t+1+\tau}\left(k_{t+1+\tau}\right)\right\} .
$$

The surplus to the firm from filling the job is $J_{f t}\left(A_{t}^{d}\left(k_{t}\right)\right)-\beta J_{v t+1}\left(k_{t+1}\right)$. Similarly, if an unemployed worker is hired by the deviating firm in period $t$, the worker receives a path of wage shares $\mathcal{A}_{t}^{d}\left(k_{t}\right)$ until the pair separates. The present value of the match to the worker is $V_{e t}\left(\mathcal{A}_{t}^{d}\left(k_{t}\right)\right)$. Similar to (4.4), I have:

$$
V_{e t}\left(\mathcal{A}_{t}^{d}\left(k_{t}\right)\right)=\sum_{\tau=0}^{\infty} a^{\tau}\left[A_{t+\tau}^{d}\left(k_{t}\right) F\left(k_{t}\right)+\sigma \beta V_{u t+1+\tau}\right] .
$$

The surplus is $V_{e t}\left(\mathcal{A}_{t}^{d}\left(k_{t}\right)\right)-\beta V_{u t+1}$ to the worker. ${ }^{14}$

Let $p_{t}^{d}\left(k_{t}\right)$ be the probability with which each unemployed worker applies to the deviator. The deviator has a tightness $\lim u_{t} p_{t}^{d}\left(k_{t}\right) \equiv B_{t}^{d}\left(k_{t}\right)$ and a matching probability $1-e^{-B_{t}^{d}\left(k_{t}\right)}$. Each unemployed worker gets the job from the deviator with a probability $\left[1-e^{-B_{t}^{d}\left(k_{t}\right)}\right] / B_{t}^{d}\left(k_{t}\right)$. Let $E S$ be expected surplus that a worker can obtain in the market, which is unaffected by a single firm's deviation (see Burdett et al., 2001). Then the deviator's wage decision solves: ${ }^{15}$

$$
E P_{t}^{d}\left(k_{t}\right) \equiv \max _{\mathcal{A}_{t}^{d}\left(k_{t}\right)}\left[1-e^{-B_{t}^{d}\left(k_{t}\right)}\right]\left[J_{f t}\left(\mathcal{A}_{t}^{d}\left(k_{t}\right)\right)-\beta J_{v t+1}\left(k_{t+1}\right)\right]
$$

subject to

$$
\frac{1-e^{-B_{t}^{d}\left(k_{t}\right)}}{B_{t}^{d}\left(k_{t}\right)}\left[V_{e t}\left(\mathcal{A}_{t}^{d}\left(k_{t}\right)\right)-\beta V_{u t+1}\right] \geq E S_{t} .
$$

\footnotetext{
${ }^{14}$ Note that, if the pair separates or if the job remains unfilled in a period, the firm reverts to the equilibrium strategy. So, the future value of a vacancy is $J_{v t+1}\left(k_{t+1}\right)$, which is unaffected by the firm's current deviation. Similarly, the continuation payoff to the worker who fails to get a match or separates from a match in $t$ is unaffected by the firm's deviation.

${ }^{15}$ This problem is equivalent to choosing the wage path to maximize the deviator's value of a vacancy, $J_{v}^{d}\left(k_{t}\right)$, which obeys $(4.3)$ with $\left(\mathcal{A}_{t}^{d}, B_{t}^{d}\right)$ replacing $\left(\mathcal{A}_{t}, B_{t}\right)$.
} 
The constraint requires that the expected surplus of a worker applying to the deviator be higher than or equal to the market surplus; otherwise, the deviator would not be able to attract any of the targeted workers. If the inequality " $>$ " is strict, then the deviator will attract all the targeted workers, which implies $B^{d} \rightarrow \infty$ and $\left(1-e^{-B^{d}}\right) / B^{d} \rightarrow 0$ in the large market, contradicting the strict inequality " $>$ ". Thus, the constraint must hold with equality.

If equilibrium wage shares are $\mathcal{A}_{t}\left(k_{t}\right)$, then there cannot be any profitable deviation. So, the above problem must be solved by $\mathcal{A}_{t}^{d}\left(k_{t}\right)=\mathcal{A}_{t}\left(k_{t}\right)$, which implies $p^{d}\left(k_{t}\right)=p\left(k_{t}\right)$ and $B_{t}^{d}\left(k_{t}\right)=$ $B_{t}\left(k_{t}\right)$. Imposing these on the first-order condition of the above problem, I have:

$$
\begin{aligned}
& V_{e t}\left(\mathcal{A}_{t}\left(k_{t}\right)\right)-\beta V_{u t+1} \\
= & \frac{B_{t}\left(k_{t}\right)}{e^{B_{t}\left(k_{t}\right)}-1}\left[V_{e t}\left(\mathcal{A}_{t}\left(k_{t}\right)\right)-\beta V_{u t+1}+J_{f t}\left(\mathcal{A}_{t}\left(k_{t}\right)\right)-\beta J_{v t+1}\left(k_{t+1}\right)\right] .
\end{aligned}
$$

This equation states that the worker's surplus from the match in terms of the present value is a share $B_{t}\left(k_{t}\right) /\left[e^{B_{t}\left(k_{t}\right)}-1\right]$ of the total match surplus.

With (4.8), a worker's expected surplus ES and the firm's expected surplus EP are as follows for given $k$ :

$$
\begin{gathered}
E S_{t}=e^{-B_{t}\left(k_{t}\right)}\left[P V\left(k_{t}\right)-\xi_{t}\right] \\
E P_{t}\left(k_{t}\right)=\left[1-\left(1+B_{t}\left(k_{t}\right)\right) e^{-B_{t}\left(k_{t}\right)}\right]\left[P V\left(k_{t}\right)-\xi_{t}\right],
\end{gathered}
$$

where $P V$ is defined in (3.1) and

$$
\xi_{t} \equiv \beta\left[V_{u t+1}+J_{v t+1}\left(k_{t+1}\right)\right]-\sigma \beta \sum_{\tau=0}^{\infty} a^{\tau}\left[V_{u t+1+\tau}+J_{v t+1+\tau}\left(k_{t+1+\tau}\right)\right]
$$

\subsection{Market tightness and assignment}

Now I determine the choice of machine qualities. To do so, I need to specify the market tightness schedule $\left\{B_{t}\left(k_{t}, s\right)\right\}_{s \in S, k_{t} \in R_{+}, t \geq 0}$. This schedule ensures the value of a vacancy to be zero for all possible pairs $\left(k_{t}, s\right)$ and all $t \geq 0$, i.e., $J_{v t}\left(k_{t}, s\right)=0$ for all $\left(k_{t}, s\right)$ and all $t$, provided that output from the pair $\left(k_{t}, s\right)$ is at least as high as the cost of the machine. If output from a pair $\left(k_{t}, s\right)$ is less than the machine cost, then $J_{v t}\left(k_{t}, s\right)<0$, in which case no firm will choose $k_{t}$ for $s$ in period $t$ and so $B_{t}\left(k_{t}, s\right)=\infty$. From (4.3) one can show that

$$
J_{v t}\left(k_{t}\right)-\beta J_{v t+1}\left(k_{t+1}\right)=E P_{t}\left(k_{t}, s\right)-C\left(k_{t}\right) .
$$

With (4.10), the zero-profit condition is:

$$
\begin{cases}1-\left[1+B_{t}\left(k_{t}, s\right)\right] e^{-B_{t}\left(k_{t}, s\right)}=\frac{C\left(k_{t}\right)}{P V\left(k_{t}, s\right)-\xi_{t}}, & \text { if } C\left(k_{t}\right) \leq F\left(k_{t}, s\right) \\ B_{t}\left(k_{t}, s\right)=\infty, & \text { otherwise }\end{cases}
$$

This specifies a tightness for every pair $\left(k_{t}, s\right)$, not just for the pairs observed in equilibrium. For pairs $\left(k_{t}^{\prime}, s\right)$, where $k_{t}^{\prime} \notin \phi_{t}(s)$, (4.12) is a restriction on beliefs off the equilibrium path, 
which can be rationalized by the entry competition. That is, when contemplating the choice of a quality $k_{t}^{\prime} \notin \phi_{t}(s)$ for skill $s$, a firm expects that other firms can do the same and the perceived competition leaves each firm with a non-positive expected net profit.

Taking the schedule $\left\{B_{t}\left(k_{t}, s\right)\right\}_{s \in S, k_{t} \in R_{+}, t \geq 0}$ as given, the firms compete with each other by choosing the machine qualities to target the workers. For each skill level $s$, the choice of machine quality must then solve:

$$
\left(P^{e}\right) \max _{k_{t}}\left\{E S_{t}(s): 1-\left[1+B_{t}\left(k_{t}, s\right)\right] e^{-B_{t}\left(k_{t}, s\right)}=\frac{C\left(k_{t}\right)}{P V\left(k_{t}, s\right)-\xi_{t}}\right\} .
$$

In this problem, $\xi_{t}$ is taken as given by each recruiting firm since it depends only on future values $\left\{V_{u t+\tau}\right\}_{\tau \geq 1}$ that are determined by the actions of all firms.

\subsection{Equilibrium and efficiency}

An equilibrium is defined as follows:

Definition 4.1. An equilibrium consists of an assignment $\phi$, a path of wage shares $\mathcal{A}$, and a schedule of market tightness $B$ such that the following conditions hold:

(i) For each pair $(k, s)$, the tightness $B(k, s)$ satisfies (4.12);

(ii) Given the tightness schedule and that other firms' choices follow the equilibrium path, it is ex ante optimal for a firm to choose a quality $k \in \phi(s)$ to target skill $s$ workers and post the path of wage shares $\mathcal{A}$.

Compare the equilibrium problem $\left(P^{e}\right)$ with the social planner's problem $\left(P^{\prime \prime}\right)$. These two problems are identical to each other iff $\xi=\lambda$. Because $\xi=\lambda$ indeed, as shown in Appendix B, the following proposition holds.

Proposition 4.2. (Coincide) The market assignment is identical to the efficient one for all $t$. Thus, under the conditions in Proposition Existence, $\phi_{t}(s)$ is a singleton for each $s$.

This efficiency result is much stronger than in the one-period model (Shi 2001), because the equilibrium decentralizes the efficient allocation in every period. In fact, the one-period model corresponds to the special case where $a \rightarrow 0$ (i.e., $\beta \rightarrow 0$ ). Moreover, the proof of the above proposition does not rely on the stability result that $\lambda$ is constant over time.

Key to the efficiency is the result that an unemployed worker's expected surplus in equilibrium $(E S)$ equals expected social gain from matching a worker today $(\Omega)$. Three factors are important for this equality. First, the decision rights are allocated properly. The agents who actively create matches, i.e., the firms, decide the split of the match surplus by posting wages. In contrast to the arbitrary surplus division through ex post Nash bargaining (e.g., Diamond 1982, Mortensen 1982, and Pissarides 1990), the proper allocation of decision rights ensures that the wage share reflects 
workers' marginal contribution to the social surplus, a reminiscence of the condition identified by Hosios (1990). Second, there is full-fledged competition, not only in the sense of free entry of firms but also in the sense that each worker knows the wages posted by all firms (but see footnote 12). In contrast to limited competition in the search literature surveyed in McMillan (1994), where each worker finds one wage at a time, full-fledged competition ensures that firms select the machine quality to maximize the skill's social marginal value. Finally, firms can commit to the posted wage and to the specific skill they advertized for. This enables firms to target an optimal machine quality to each skill, thus inducing ex ante efficiency, although the firms may have incentive to consider a different skill ex post when it fails to be matched.

Equilibrium wages in the above market mechanism are equal to efficient compensations to skills. Recovering $w(s)$ from (4.8), one can verify that it coincides with (3.27). Since $\left(\phi_{t}, b_{t}\right)$ are constant over time by Proposition Stable, the wage rate $w_{t}(s)$ is also constant over time.

\section{Each Machine Is Assigned to a Single Skill}

In previous sections I have presumed that each machine is assigned to a unique skill. In this section I show that this is an endogenous outcome. Then I discuss Assumption Not-lexicographic that is used for establishing this one-to-one feature of the assignment.

\subsection{One-to-one assignment}

Consider a multiple-skill assignment $\phi^{d}$ that assigns each machine of a particular quality $k^{d}$ to match with both skills $s_{1}$ and $s_{2}$, where $s_{1}>s_{2}$. Without loss of generality, assume that $k^{d}$ is the only machine quality that receives multiple assignments and the only machine quality assigned to $s_{1}$ and $s_{2}$. Let period $\tau$ be the period in which the multiple-skill assignment occurs. I will describe the efficiency requirements in period $\tau$, but often suppress the subscript $\tau$. Let $Q$ be the number of quality $k^{d}$ machines and $q_{i} Q$ the number of unemployed skill $s_{i}$ workers assigned to match with each other in period $\tau$, where $i=1,2$. Refer to this group of machines and workers as unit $\left(k^{d}, s_{1}, s_{2}\right)$. The variables $\left(q_{1}, q_{2}, Q, k^{d}\right)$ are choices.

Because the assignment $\phi^{d}$ allocates multiple skills to match with a machine, it must specify how the skills are selected ex post (after match) to produce with the machine. Let $x_{i}$ be the probability that the worker selected for a quality $k^{d}$ machine is a skill $s_{i}$ worker, conditional on that both skills show up at the match, where $i=1,2$. Clearly, $x_{1}+x_{2}=1$. By choosing $\left(x_{1}, x_{2}\right)$, the assignment can give one of the two skills a higher selection priority probabilistically. However, Assumption Not-lexicographic requires $0<x_{i}<1$ for $i=1,2 .{ }^{16}$

In the presence of the multiple-skill assignment, I must modify the matching rates. Let $i^{\prime} \neq i$ and $i, i^{\prime} \in\{1,2\}$. Consider a particular machine in the unit $\left(k^{d}, s_{1}, s_{2}\right)$. When targeting the two

\footnotetext{
${ }^{16}$ Here $x_{1}$ and $x_{2}$ are independent of the numbers of skill $s_{1}$ and $s_{2}$ workers that the machine receives, provided that the machine receives both. This assumption simplifies the calculation, but it is not critical for the result.
} 
skills, a machine will be paired with a skill $s_{i}$ worker with the following probability:

$$
\left(1-e^{-q_{i}}\right)\left[e^{-q_{i^{\prime}}}+x_{i}\left(1-e^{-q_{i^{\prime}}}\right)\right] .
$$

The explanation is as follows. For the machine to pair with a skill $s_{i}$ worker, one or more skill $s_{i}$ workers must apply to the job, which occurs with probability $\left(1-e^{-q_{i}}\right)$. In this case, the job is given to a skill $s_{i}$ worker either because no skill $s_{i^{\prime}}$ worker has applied to the job, which occurs with probability $e^{-q_{i^{\prime}}}$, or because some skill $s_{i^{\prime}}$ workers have applied but none of them is chosen, which occurs with probability $x_{i}\left(1-e^{-q_{i^{\prime}}}\right)$.

Proposition 5.1. (One-to-one) Under Assumption Not-lexicographic, it is neither socially efficient nor consistent with an equilibrium to assign each machine to multiple skill levels.

Consider the efficient assignment first. For the unit $\left(k^{d}, s_{1}, s_{2}\right)$, the social planner chooses $\left(k^{d}, Q, q_{1}, q_{2}\right)$ and $\left(x_{1}, x_{2}\right)$. When a machine $k^{d}$ pairs with a skill $s_{i}$ worker, it generates a social value $P V\left(k^{d}, s_{i}\right)$. The expected surplus generated by all machines and workers in the unit is

$$
E V\left(k^{d}, s_{1}, s_{2}\right) \equiv Q\left\{\begin{array}{l}
\left(1-e^{-q_{1}}\right)\left[e^{-q_{2}}+x_{1}\left(1-e^{-q_{2}}\right)\right] P V\left(k^{d}, s_{1}\right) \\
+\left(1-e^{-q_{2}}\right)\left[e^{-q_{1}}+x_{2}\left(1-e^{-q_{1}}\right) P V\left(k^{d}, s_{2}\right)\right]-C\left(k^{d}\right)
\end{array}\right\}
$$

Let $Z$ be the collection of subsets of $S$ to which $\phi^{d}$ assigns machines, with $z \in Z$ being a typical element. The objective of the efficient allocation then becomes

$$
\beta^{\tau} E V\left(k^{d}, s_{1}, s_{2}\right)+\sum_{t=0}^{\infty} \beta^{t} \sum_{z \in Z_{t}} \sum_{k_{t} \in K_{t}^{d}(z)} E V\left(k_{t}, z\right)
$$

where $K_{t}^{d}(z)=\emptyset$ if $t=\tau$ and $z=\left\{\left(s_{1}, s_{2}\right)\right\}$; otherwise, $K_{t}^{d}(z)=\phi_{t}^{d}(z)$.

The constraints (3.5) and (3.6) must also be revised for $s_{i}$. Focusing on period $\tau$ and using subscript $+t$ to stand for $\tau+t$, the following constraints must hold for $i=1,2$ :

$$
\begin{aligned}
& u_{+1}\left(s_{i}\right)=\sigma\left(s_{i}\right) n\left(s_{i}\right)+\left[1-\sigma\left(s_{i}\right)\right]\left\{u\left(s_{i}\right)-\left(1-e^{-q_{i}}\right)\left[e^{-q_{i^{\prime}}}+x_{i}\left(1-e^{-q_{i^{\prime}}}\right)\right] Q\right\}, \\
& q_{i} Q=u\left(s_{i}\right) .
\end{aligned}
$$

Let the multiplier of the first constraint be $\lambda^{d}\left(s_{i}\right) /\left[1-\sigma\left(s_{i}\right)\right]$ and of the second constraint $\Omega^{d}\left(s_{i}\right)$. Then, the social marginal value of current unemployed $s_{i}$ workers is $\lambda_{-1}^{d}\left(s_{i}\right) /\left[1-\sigma\left(s_{i}\right)\right]$. The value $\lambda^{d}$ must satisfy a transversality condition similar to (3.8).

Suppose, contrary to Proposition One-to-one, that the above multiple-skill assignment is efficient. Because $x_{1}$ and $x_{2}$ must lie in the interior of $(0,1)$, their first-order conditions imply:

$$
P V\left(k^{d}, s_{1}\right)-\lambda^{d}\left(s_{1}\right)=P V\left(k^{d}, s_{2}\right)-\lambda^{d}\left(s_{2}\right) .
$$

That is, a current match must yield the same surplus, no matter a skill $s_{1}$ or $s_{2}$ worker is selected ex post. If the economy lasts for only one period, $a\left(s_{i}\right)=0$ and $\lambda^{d}\left(s_{i}\right)=0$. Because $P V(k, s)$ is 
an increasing function of $s$, the above condition is violated in this case and so the multiple-skill assignment is not efficient. When the economy lasts for an infinite horizon, I invoke the stability requirement to derive a contradiction. The procedure is as follows.

First, I derive the first-order conditions for $\left(q_{1}, q_{2}, Q, k^{d}\right)$. Clearly, $Q>0, q_{1}>0$ and $q_{2}>0$ for the unit $\left(k^{d}, s_{1}, s_{2}\right)$ to be a part of the efficient assignment. Denote $q \equiv q_{1}+q_{2}$. Under (5.1), the first-order conditions for $\left(q_{i}, Q, k^{d}\right)$ and the envelope condition for $u\left(s_{i}\right)$ are as follows:

$$
\begin{gathered}
\Omega^{d}\left(s_{1}\right)=\Omega^{d}\left(s_{2}\right)=e^{-q}\left[P V\left(k^{d}, s_{1}\right)-\lambda^{d}\left(s_{1}\right)\right], \\
{\left[1-(1+q) e^{-q}\right]\left[P V\left(k^{d}, s_{1}\right)-\lambda^{d}\left(s_{1}\right)\right]=C\left(k^{d}\right),} \\
C_{k}\left(k^{d}\right)=\left\{\begin{array}{c}
{\left[e^{-q_{2}}+x_{1}\left(1-e^{-q_{2}}\right)\right]\left(1-e^{-q_{1}}\right) P V_{k}\left(k^{d}, s_{1}\right)} \\
+\left[e^{-q_{1}}+x_{2}\left(1-e^{-q_{1}}\right)\right]\left(1-e^{-q_{2}}\right) P V_{k}\left(k^{d}, s_{2}\right)
\end{array}\right\}, \\
\lambda_{-1}^{d}\left(s_{i}\right)=a\left(s_{i}\right)\left[\lambda^{d}\left(s_{i}\right)+\Omega^{d}\left(s_{i}\right)\right], \text { for } i=1,2 .
\end{gathered}
$$

These conditions can be interpreted easily by adapting the interpretations for the corresponding conditions in the single-skill assignment. In particular, (5.2) requires that the tightness $q_{i}$ equate expected social surpluses generated by assigning skills $s_{1}$ and $s_{2}$ to quality $k^{d}$ machines.

Second, because $0<x_{i}<1$ for $i \in\{1,2\}$ and $P V_{k}\left(k^{d}, s_{1}\right)>P V_{k}\left(k^{d}, s_{2}\right)$, (5.4) implies

$$
\left(1-e^{-q}\right) P V_{k}\left(k^{d}, s_{1}\right)>C_{k}\left(k^{d}\right)>\left(1-e^{-q}\right) P V_{k}\left(k^{d}, s_{2}\right) .
$$

Moreover, (5.1), (5.3) and (5.2) solve for $\left(k^{d}, q, \Omega^{d}\right)$ as functions of $\left(\lambda^{d}\left(s_{1}\right), \lambda^{d}\left(s_{2}\right)\right)$. Denote the function for $\Omega^{d}$ as $\Omega^{d}=G\left(\lambda^{d}\left(s_{1}\right), \lambda^{d}\left(s_{2}\right)\right)$ and $G_{i}$ the derivative of $G$ with respect to the $i$ th argument. Then,

$$
G_{i}=\frac{(-1)^{i}\left[C_{k}\left(k^{d}\right)-\left(1-e^{-q}\right) P V_{k}\left(k^{d}, s_{i^{\prime}}\right)\right]}{P V_{k}\left(k^{d}, s_{1}\right)-P V_{k}\left(k^{d}, s_{2}\right)}, \text { for } i, i^{\prime} \in\{1,2\} \text { and } i^{\prime} \neq i .
$$

The condition (5.6) implies $G_{1}<0$ and $G_{2}<0$. Also $G_{1}+G_{2}+1>0$.

Third, I invoke the stability requirement. Suppose that the multiple-skill assignment converges to a steady state, where the social marginal value of $s_{i}$ workers is denoted $\lambda^{d *}\left(s_{i}\right)$. Linearizing (5.5) around the steady state, I have:

$$
\left(\begin{array}{ll}
\lambda_{-1}^{d}\left(s_{1}\right)-\lambda^{d *}\left(s_{1}\right) \\
\lambda_{-1}^{d}\left(s_{2}\right)-\lambda^{d *}\left(s_{2}\right)
\end{array}\right)=\left[\begin{array}{ll}
a\left(s_{1}\right)\left(1+G_{1}\right) & a\left(s_{1}\right) G_{2} \\
a\left(s_{2}\right) G_{1} & a\left(s_{2}\right)\left(1+G_{2}\right)
\end{array}\right]\left(\begin{array}{l}
\lambda^{d}\left(s_{1}\right)-\lambda^{d *}\left(s_{1}\right) \\
\lambda^{d}\left(s_{2}\right)-\lambda^{d *}\left(s_{2}\right)
\end{array}\right) .
$$

The properties of $G_{i}$ and the fact $a\left(s_{1}\right) \geq a\left(s_{2}\right)$ imply that the two eigenvalues of the Jacobian matrix in the above system are both less than or equal to $a\left(s_{1}\right)$, and hence strictly less than $\beta$.

The same result for the eigenvalues holds for any period where the multiple-skill assignment applies. Also, the proof of Proposition Stable establishes a similar result for a single-skill assignment. Thus, for all $t \geq 0$, the eigenvalues of the Jacobian matrix of the system that links 
$\left(\lambda_{+(t-1)}^{d}\left(s_{1}\right), \lambda_{+(t-1)}^{d}\left(s_{2}\right)\right)$ to $\left(\lambda_{+t}^{d}\left(s_{1}\right), \lambda_{+t}^{d}\left(s_{2}\right)\right)$ are strictly less than $\beta$, regardless of how long the multiple-skill assignment will last. If $\lambda_{+(t-1)}^{d}\left(s_{i}\right) \neq \lambda^{d *}\left(s_{i}\right)$ for any $t \geq 0$ and $i \in\{1,2\}$, then $\lim _{T \rightarrow \infty} \beta^{T} \lambda_{+T}^{d}\left(s_{i}\right) \neq 0$, which violates the transversality condition. Therefore, the system must have $\lambda_{+(t-1)}^{d}\left(s_{i}\right)=\lambda^{d *}\left(s_{i}\right)$ for all $t \geq 0$. Similarly, $\Omega_{+t}^{d}$ is constant over time. I will then suppress the superscript $*$ below.

Finally, I deduce a contradiction to (5.1). Setting $\lambda_{-1}^{d}\left(s_{i}\right)=\lambda^{d}\left(s_{i}\right)$ in (5.5) to calculate $\lambda^{d}\left(s_{i}\right)$ and using the definition of $P V$, I have

$$
P V\left(k^{d}, s_{i}\right)-\lambda^{d}\left(s_{i}\right)-C\left(k^{d}\right)-\Omega^{d}=\frac{1}{1-a\left(s_{i}\right)}\left[F\left(k^{d}, s_{i}\right)-C\left(k^{d}\right)-\Omega^{d}\right] .
$$

Note that $\Omega^{d}$ is the same for $s_{1}$ and $s_{2}$ by (5.2). The cost $C\left(k^{d}\right)$ is also the same for $s_{1}$ and $s_{2}$. Since (5.2) and (5.3) imply $P V\left(k^{d}, s_{i}\right)-\lambda^{d}\left(s_{i}\right)-C\left(k^{d}\right)-\Omega^{d}=q \Omega^{d}>0$, it is clear that $F\left(k^{d}, s_{i}\right)-C\left(k^{d}\right)-\Omega^{d}>0$ for $i=1,2$. Then, the right-hand side of (5.7) is larger for $i=1$ than for $i=2$, implying a contradiction to (5.1). Therefore, it is socially inefficient to assign each machine to multiple skills.

Now I show that the multiple-skill assignment is also inconsistent with an equilibrium. Suppose that a firm uses the above multiple-skill assignment $\phi^{d}$ in a period $\tau$. Call this firm the deviating firm. Use the subscript $+t$ to stand for $\tau+t$. Let $A_{(+t)}^{d}\left(s_{i}\right)$ be the wage share (of output) that this firm promises to pay to an $s_{i}$ worker in period $\tau+t$. The share path is $\mathcal{A}^{d}\left(s_{i}\right)=\left\{A_{(+t)}^{d}\left(s_{i}\right)\right\}_{t \geq 0}$, which is announced at time $\tau$. I suppress the machine quality $k^{d}$ whenever it is possible.

Denote $p_{i}^{d}$ as the probability with which each $s_{i}$ worker applies to this firm. Let $q_{i}=\lim u_{i} p_{i}^{d}$. For the firm to attract $s_{i}$ workers, $q_{i}>0$. The deviating firm's expected surplus is

$$
\begin{aligned}
E P^{d}= & \left(1-e^{-q_{1}}\right)\left[e^{-q_{2}}+x_{1}\left(1-e^{-q_{2}}\right)\right]\left[J_{f}^{d}\left(s_{1}\right)-\beta J_{v(+1)}\right] \\
& +\left(1-e^{-q_{2}}\right)\left[e^{-q_{1}}+x_{2}\left(1-e^{-q_{1}}\right)\right]\left[J_{f}^{d}\left(s_{2}\right)-\beta J_{v(+1)}\right] .
\end{aligned}
$$

Here the hiring probabilities have the same expressions as in the planner's problem and $J_{f}^{d}\left(s_{i}\right)$ is the present value to the firm from hiring an $s_{i}$ worker. Similar to (4.6), I have:

$$
J_{f}^{d}\left(s_{i}\right)=\sum_{t=0}^{\infty}\left[a\left(s_{i}\right)\right]^{t}\left[\left(1-A_{(+t)}^{d}\left(s_{i}\right)\right) F\left(k^{d}, s_{i}\right)-a\left(s_{i}\right) C\left(k^{d}\right)+\sigma\left(s_{i}\right) \beta J_{v(+t+1)}\right] .
$$

The deviator maximizes $E P^{d}$ subject to the following participation constraints:

$$
\left[e^{-q_{i^{\prime}}}+x_{i}\left(1-e^{-q_{i^{\prime}}}\right)\right] \frac{1-e^{-q_{i}}}{q_{i}}\left[V_{e}^{d}\left(s_{i}\right)-\beta V_{u(+1)}\left(s_{i}\right)\right] \geq E S_{i}, \text { for } i=1,2,
$$

where $V_{u}\left(s_{i}\right)$ is the market value of an unemployed $s_{i}$ worker and $E S_{i}$ the expected surplus of an $s_{i}$ worker in the market. The employment probability of an $s_{i}$ applicant to the deviator can be intuitively understood as the probability with which the firm hires an $s_{i}$ worker, divided by 
the expected number of $s_{i}$ applicants that the firm receives $\left(q_{i}\right)$. The value function $V_{e}^{d}\left(s_{i}\right)$ is the sum of discounted values to an $s_{i}$ worker employed by the deviator. Similar to (4.7), I have:

$$
V_{e}^{d}\left(s_{i}\right)=\sum_{t=0}^{\infty}\left[a\left(s_{i}\right)\right]^{t}\left[A_{+t}^{d}\left(s_{i}\right) F\left(k^{d}, s_{i}\right)+\sigma\left(s_{i}\right) \beta V_{u(+t+1)}\left(s_{i}\right)\right] .
$$

Under the maintained assumption $x_{i} \in(0,1)$ for $i=1,2$, the first-order conditions for $x_{i}$ must hold. Combining these conditions with the first-order conditions for $\left(A_{+t}\left(s_{1}\right), A_{+t}\left(s_{2}\right)\right)$ and the equilibrium condition $J_{v t}=0$ for all $t$, I have

$$
J_{f}^{d}\left(s_{1}\right)+V_{e}^{d}\left(s_{1}\right)-\beta V_{u(+1)}\left(s_{1}\right)=J_{f}^{d}\left(s_{2}\right)+V_{e}^{d}\left(s_{2}\right)-\beta V_{u(+1)}\left(s_{2}\right) .
$$

The formulas of $J_{f}^{d}$ and $V_{e}^{d}$ imply

$$
J_{f}^{d}\left(s_{i}\right)+V_{e}^{d}\left(s_{i}\right)-\beta V_{u(+1)}\left(s_{i}\right)=P V^{d}\left(s_{i}\right)-\xi\left(s_{i}\right),
$$

where $\xi$ is defined in (4.11) (note that $J_{v}=0$ ). Since $\xi\left(s_{i}\right)=\lambda\left(s_{i}\right)$, as shown in Appendix B, the condition (5.8) is identical to (5.1). So, the same procedure can be used to show that this condition is violated. This completes the proof of Proposition One-to-one.

\subsection{Discussion}

In similar environments but with only one period, Shi (forthcoming) and Shimer (2001a) have shown that the efficient assignment is lexicographic. Since efficiency is the focus in the current paper, it is necessary to explain why I exclude lexicographic assignments.

The primary reason is tractability. Lexicographic assignments can be exceedingly complicated in an infinite-horizon economy. To see this, suppose that a quality $k$ machine is assigned to match with skills $\left(s_{1}, s_{2}, s_{3}\right)$, with the lexicographic selection rule that $s_{1}$ is selected before $s_{2}$ and $s_{2}$ before $s_{3}$, where $s_{1}>s_{2}>s_{3}$. Because there are many other quality $k$ machines and there is a lack of coordination, each quality $k$ machine fails to receive a skill $s_{1}$ worker with a strictly positive probability. Suppose that this failure occurs but the machine receives one or more skill $s_{2}$ worker. In this case, it may be optimal to award the job in the current period to a skill $s_{2}$ worker and continue to search for an $s_{1}$ worker next period. So, the assignment next period will depend directly on the distribution of received workers in the current period, as well as the number of unemployed workers available for matches next period. Since the firm may again fail to receive an $s_{1}$ worker next period, the assignment two periods in the future will depend on the distributions of received workers in the current and next period. In the end, the assignment will depend on the distributions of received workers in all past periods. To solve for the efficient (or equilibrium) assignment, one must solve for the entire time-path of the skill distributions over 
the machines of each quality, and do so for all machine qualities employed. It is very difficult to solve for these distributions. ${ }^{17}$

The complexity arises in two other related dimensions. First, with a multiple skill assignment, the threshold skill level assigned to match with a particular machine quality may vary over time. As in Shimer (2001b), the efficient assignment may never converge to a steady state. Second, lexicographic assignments seem inconsistent with the assumption that only unemployed workers participate in the matching process. There is a gain in efficiency from allowing machines that are matched but not with the most desirable workers to continue to seek for a better match. Allowing for such on-the-job search in a directed-search environment is an interesting direction of research yet to be explored.

Moreover, lexicographic assignments are special mechanisms that allow the allocation to be conditional on the realization of the matching process. So are various types of auction (see Julien et al. 2000). The class of such assignments can be very large, depending on what the assignments are allowed to be conditional on. It is not clear which degree of conditioning is more reasonable.

Finally, the assignment under Assumption Not-lexicographic provides a benchmark against which one can measure the additional efficiency gain from allowing for lexicographic assignments. When lexicographic assignments are permitted, it is still true that the most preferred skill for each machine is unique. The other skills assigned to match with the same machine are just "back-ups", and they increase efficiency only when the most preferred skill fails to show up at the match. This gain is much smaller than the gain emphasized in the current paper, namely, that achieved by switching from an undirected search to directed search.

\section{Conclusion}

In this paper I study the assignment between machines of heterogeneous qualities and workers of heterogeneous skills in an infinite-horizon economy with matching frictions. I first characterize the efficient allocation and then the decentralizing market equilibrium.

The efficient assignment has the following properties. (i) The assignment is one-to-one, i.e., it assigns the workers of each skill to a unique quality of machines. (ii) It is dynamically stable. (iii) The efficient assignment is non-positive in every period if skills and machine qualities are not sufficiently complementary with each other. (iv) If the machine quality assignment is nonpositive, then high-skill workers must have higher matching rates than low-skill workers. (v) Efficient wage rates are increasing functions of the skill level when the assignment is positive, but not always so when the assignment is non-positive. The marginal compensations for skills are less than the skills' marginal products if and only if high-skill workers have higher matching rates

\footnotetext{
${ }^{17}$ Such distributions are unimportant only when the firm is indifferent between the skill levels it chooses to target. This indifference is precisely what Assumption Not-lexicographic imposes on multiple-skill assignments and why it makes the analysis tractable here.
} 
than low-skill workers. (vi) Finally, the social value of workers always increases in the skill level, regardless of the assortative property of the assignment.

A particular market mechanism can decentralize the entire time path of the efficient assignment. In this mechanism, the firms enter the market in each period under free entry and compete for workers by announcing the machine qualities they choose, the skill levels to which the machines are targeted, and wage rates. Important for efficiency is that the firms commit to the announced machines, skills and wages. Those announcements direct the workers' search and internalize matching externalities.

Saddle-path stability plays an important role in establishing the above results. Along the stable path, the social value of workers is constant over time to ensure that the trade-off between current and future matches is efficient. Also, the machine quality, the market tightness, and the wage rate for each skill are all time-invariant.

The results in this paper not only predict the patterns of the assignment and wage inequality in the steady state, they are also useful for analyzing how these patterns respond dynamically to shocks. For example, consider an unanticipated reduction in the cost of producing machines. At the time of the shock, the assignment jumps immediately to the new steady state level. That is, unemployed workers are assigned to match with the new machine quality. In contrast, workers who were employed at the time of the shock will stay with the old machine assignments; only after separation will they be assigned for matches according to the new steady state assignment. Because workers of the same skill are matched with different machine qualities during the transition, the assignment is mixed at the aggregate level. Consequently, there is a wage differential among workers of the same skill. This within-group wage inequality disappears as the economy converges to the new steady state. These dynamic responses may be useful for explaining the observed time pattern of wage inequality in recent decades.

I have abstracted from many realistic aspects of the labor market, and so the model allows for useful extensions in the future. On the assignment, one can introduce multi-dimensional skills, match-specific productivity, private information and/or uncertainty in productivity. With these elements one can examine how firms use wages to retain workers and reveal productivity, in addition to the ex ante role of attracting workers. On inequality, one can introduce human capital accumulation and analyze how inequality can persist along a balanced growth path. 


\section{References}

[1] D. Acemoglu and R. Shimer, Holdups and efficiency with search frictions, International Economic Review 40 (1999), 827-850.

[2] G.S. Becker, A theory of marriage: part I, Journal of Political Economy 81 (1973), 813-846.

[3] K. Burdett and M. Coles, Marriage and class, Quarterly Journal of Economics 112 (1997), 141-168.

[4] K. Burdett, S. Shi and R. Wright, Matching and pricing with frictions, Journal of Political Economy 109 (2001), 1060-1085.

[5] K. Burdett and R. Wright, Two-sided search with nontransferable utility, Review of Economic Dynamics 1 (1998), 220-245.

[6] M. Cao and S. Shi, Coordination, matching, and wages, Canadian Journal of Economics 33 (2000), 1009-1033.

[7] P. Diamond, Aggregate demand management in search equilibrium, Journal of Political Economy 90 (1982), 881-894.

[8] A. Hosios, On the efficiency of matching and related models of search and unemployment, Review of Economic Studies 57 (1990), 279-298.

[9] B. Julien, J. Kennes and I. King, Bidding for labor, Review of Economic Dynamics 3 (2000), 619-649.

[10] J. McMillan and M. Rothschild, Search, in "Handbook of Game Theory" (R. Aumann and S. Hart, Eds.), vol. 2, pp.905-927, North-Holland, Amsterdam, 1994.

[11] E.R. Moen, Competitive search equilibrium, Journal of Political Economy 105 (1997), 385411.

[12] J.D. Montgomery, Equilibrium wage dispersion and interindustry wage differentials, Quarterly Journal of Economics 106 (1991), 163-179.

[13] D. Mortensen, Property rights and efficiency in mating, racing, and related games, American Economic Review 72 (1982), 968-979.

[14] M. Peters, Ex ante price offers in matching games: non-steady state, Econometrica 59 (1991), $1425-2454$.

[15] M. Peters and A. Siow, Competing premarital investments, Journal of Political Economy 110 (2002), 592-608.

[16] C. Pissarides, "Equilibrium Unemployment Theory," Basil Blackwell, Cambridge, Massachusetts, 1990.

[17] M. Sattinger, Search and the efficient assignment of workers to jobs, International Economic Review 36 (1995), 283-302.

[18] S. Shi, Frictional assignment, manuscript, Queen's University (http://ideas.uqam.ca/CREFE/publicationse.html), 1998.

[19] S. Shi, Frictional assignment, part I, efficiency, Journal of Economic Theory 98 (2001), 232-260. 
[20] S. Shi, A directed-search model of inequality with heterogeneous skills and skill-biased technology, Review of Economic Studies (forthcoming).

[21] R. Shimer, The assignment of workers to jobs in an economy with coordination frictions, manuscript, Princeton University, 2001a.

[22] R. Shimer, Nonstationary search, manuscript, Princeton University, 2001b.

[23] R. Shimer and L. Smith, Assortative matching and search, Econometrica 68 (2000), 343-370.

[24] J. Tinbergen, Some remarks on the distribution of labour incomes, International Economic Papers 1 (1951). Translations prepared for the international economic association (A.T. Peacock et al., Eds.), pp.195-207, Macmillan, London, 1951. 


\section{Appendix}

\section{A. Proof of Proposition Existence}

First, let me reformulate the problem $\left(P^{\prime \prime}\right)$. Denote $\Theta(x)=1-(1+x) e^{-x}$. Since $\Theta(x)$ is strictly increasing for all $x>0$, its inverse exists which is denoted $\theta(\cdot)$. Then, (3.9) can be rewritten as $B(k, s)=\theta\left(\frac{C(k)}{P V(k, s)-\lambda(s)}\right)$. The problem $\left(P^{\prime \prime}\right)$ can be rewritten as $\max \omega(k, s)$, where

$$
\omega(k, s) \equiv e^{-\theta\left(\frac{C(k)}{P V(k, s)-\lambda(s)}\right)}[P V(k, s)-\lambda(s)] .
$$

Since this problem involves only skill $s$ workers, I suppress the index $s$ in this proof.

Next, let me find the bounds on the maximizers of $\omega(k)$. For the upper bound, notice that $\theta^{\prime}=e^{\theta} / \theta=\left(1-e^{-\theta}-\frac{C(k)}{P V(k)-\lambda}\right)^{-1}$ and calculate

$$
\omega^{\prime}(k)=\frac{1}{\theta}\left\{\frac{1-e^{-\theta}}{1-a}\left(F_{k}-a C_{k}\right)-C_{k}\right\} .
$$

Any maximizer of $\omega(k)$ must satisfy $C_{k} \leq F_{k}$; otherwise $\omega^{\prime}(k)<0$, in which case $\omega(k)$ could be increased by reducing $k$. Since $k_{\max }$ satisfies $C_{k}=F_{k}$ and since $\left(C_{k}-F_{k}\right)$ is an increasing function of $k$, the requirement $C_{k} \leq F_{k}$ is equivalent to $k \leq k_{\max }$ for all $k \in \phi^{o}$.

The lower bound on the maximizer of $\omega(k)$ is $k_{\min }$. To see this, note that the function $\left[F(k) C_{k}(k)-C(k) F_{k}(k)\right]$ is an increasing function of $k$. It is negative at $k=0$ and positive at $k=k_{\max }$. Thus, $k_{\min }$ is well-defined and $k_{\min }<k_{\max }$. Suppose that $k^{\prime}$ maximizes $\omega(k)$, with $k^{\prime}<k_{\min }$. Then $F\left(k^{\prime}\right) C_{k}\left(k^{\prime}\right) \leq C\left(k^{\prime}\right) F_{k}\left(k^{\prime}\right)$, and so

$$
\begin{aligned}
\omega^{\prime}\left(k^{\prime}\right. & >\frac{1}{\theta}\left\{\frac{1-(1+\theta) e^{-\theta}}{1-a}\left[F_{k}\left(k^{\prime}\right)-a C_{k}\left(k^{\prime}\right)\right]-C_{k}\left(k^{\prime}\right)\right\} \\
& =\frac{1}{\theta}\left\{\frac{C\left(k^{\prime}\right)}{(1-a)\left(P V\left(k^{\prime}\right)-\lambda\right)}\left[F_{k}\left(k^{\prime}\right)-a C_{k}\left(k^{\prime}\right)\right]-C_{k}\left(k^{\prime}\right)\right\} \\
& =\frac{1}{\theta\left[P V\left(k^{\prime}\right)-\lambda\right]}\left\{\frac{1}{1-a}\left[C\left(k^{\prime}\right) F_{k}\left(k^{\prime}\right)-F\left(k^{\prime}\right) C_{k}\left(k^{\prime}\right)\right]+C_{k}\left(k^{\prime}\right) \lambda\right\} \\
& >0 .
\end{aligned}
$$

The first equality follows from (3.9), and the last inequality from the supposed condition $C\left(k^{\prime}\right) F_{k}\left(k^{\prime}\right) \geq$ $F\left(k^{\prime}\right) C_{k}\left(k^{\prime}\right)$. Since $\omega^{\prime}\left(k^{\prime}\right)>0$, and $k_{\min }\left(>k^{\prime}\right)$ is feasible, $k^{\prime}$ cannot possibly maximize $\omega(k)$. A contradiction. Thus, all solutions for $k$ must be greater than or equal to $k_{\min }$.

The above arguments show that $\omega^{\prime}(k)>0$ at $k=k_{\min }$ and $\omega^{\prime}(k)<0$ at $k=k_{\max }$. Thus, $\omega(k)$ has at least one maximum in $\left(k_{\min }, k_{\max }\right)$, and all such maxima satisfy $\omega^{\prime}(k)=0$. To show that $\omega(k)$ has a unique maximum, it suffices to show that $\omega^{\prime \prime}(k)<0$ whenever $\omega^{\prime}(k)=0$ in the domain $\left(k_{\min }, k_{\max }\right)$ (If $\omega(k)$ has a second maximum, then it must also have a minimum, at which $\omega^{\prime \prime}(k)>0$.) The latter requirement is equivalent to

$$
F_{k} C_{k k}-C_{k} F_{k k}>\frac{F_{k}-C_{k}}{1-a} \cdot \frac{\left[F_{k}-a C_{k}\right]^{2}}{F-a C-(1-a) \lambda},
$$

which is guaranteed by (3.15) for all $\lambda<\bar{\lambda}$.

QED

\section{B. Proofs of Propositions Stable and Coincide}

For Proposition Stable, recall that $\Omega=e^{-b}(P V-\lambda)$ and $d \Omega / d \lambda<0$. Then, $0<\Psi^{\prime}(\lambda)<a<\beta$. When $\lambda=0, \phi(0) \in\left(k_{\min }, k_{\max }\right)$ and $b(\phi(0)) \in(0, \infty)$. Thus, $\Psi(0)>0$. When $\lambda$ is sufficiently 
large so that the right-hand side of (3.19) approaches one, $b \rightarrow \infty, \phi \rightarrow k_{\max }$ and so $\Psi \rightarrow a \lambda<\lambda$. Since $\Psi^{\prime}>0$, these properties imply that there is a unique value $\lambda^{*}$ that satisfies $\Psi\left(\lambda^{*}\right)=\lambda^{*}$. It is then easy to see from (3.21) that there is a unique steady state value of $r u$.

To show that this steady state is locally stable, notice that the dynamics of $\lambda$ (given by (3.20)) are autonomous, except for the value at $t=0$, and that $0<\Psi^{\prime}<a$. If $\left|\lambda_{0}-\lambda^{*}\right| \neq 0$, then the sequence $\left\{\left|\lambda_{t}-\lambda^{*}\right|\right\}_{t \geq 0}$ defined by (3.20) increases monotonically at a rate greater than $1 / a>$ $1 / \beta$. This will violate the transversality condition (3.8). Thus, the only rational expectations solution is $\lambda_{t}=\lambda^{*}$ for all $t \geq 0$. This implies $\phi_{t}=\phi^{*}$ and $b\left(\phi_{t}\right)=b^{*}$ for all $t \geq 0$. Substituting $\lambda=\lambda^{*},(3.21)$ becomes a linear difference equation of $r u$, where the root is positive and less than one. So, for any initial value $r u_{0} \in(0,1)$, this equation determines a unique sequence $\left\{r u_{t}\right\}_{t \geq 0}$ that monotonically approaches $r u^{*}$.

To verify Conjecture 3.1, let $k \in \phi(s)$. (The conjecture is trivially satisfied if $k \notin \phi(s)$ for every $s \in S$.) Because quality $k$ machines are assigned only to skill $s$ workers in all periods and each machine is paired with one worker, the total number of quality $k$ machines that are employed in period $t$ before separation is $E_{t}(s)$. A fraction $\sigma-\rho$ of these machines will be vacant and undepreciated at the end of the period after separation. In addition, there are $m_{t}(s) e^{-b(s)}$ number of quality $k$ machines that failed to match in the period, a fraction $(1-\rho)$ of which will remain at the end of the period. So, the total number of quality $k$ machines that are vacant at the end of period $t$ is $(\sigma-\rho) E_{t}(s)+(1-\rho) m_{t}(s) e^{-b(s)}$. Conjecture 3.1 requires this number to be less than or equal to $m_{t+1}(s)$. Using $m_{t}(s)=u_{t}(s) / b(s), u_{t}(s)=r u_{t}(s) n(s)$, and $E_{t}(s)=\left[n(s)-u_{t+1}(s)\right] /(1-\sigma(s))$, I can be express this requirement as follows:

$$
r u_{t+1}(s) \geq(\sigma-\rho)\left[1-r u_{t+1}(s)\right] b(s) /(1-\sigma(s))+(1-\rho) r u_{t}(s) e^{-b(s)} .
$$

Calculating the steady state value of $r u$ from (3.21), one can verify that the above condition holds with strict inequality in the steady state. So, it holds in a neighborhood of the steady state. This completes the proof of Proposition Stable.

For Proposition Coincide, it suffices to show $\xi_{t}=\lambda_{t}$ for all $t$. For this, I show that the sequence $\left\{\xi_{t}\right\}_{t \geq 0}$ obeys (3.10), the process for $\lambda_{t}$. With $J_{v t}=0$ for all $t$ and with (4.11), I have:

$$
\begin{aligned}
\xi_{t} & =\beta V_{u t+1}-\sigma \beta \sum_{\tau=0}^{\infty} a^{\tau} V_{u t+1+\tau}=a\left[V_{u t+1}-\sigma \beta \sum_{\tau=0}^{\infty} a^{\tau} V_{u t+2+\tau}\right] \\
& =a\left[V_{u t+1}-\left(\beta V_{u t+2}-\xi_{t+1}\right)\right]=a\left(\xi_{t+1}+E S_{t+1}\right) \\
& =a\left\{\xi_{t+1}+e^{-B_{t+1}\left(k_{t+1}\right)}\left[P V\left(k_{t+1}, s\right)-\xi_{t+1}\right]\right\}
\end{aligned}
$$

The first equality follows from setting $J_{v t}=0$ for all $t$ in (4.11), the second equality from regrouping terms, the third equality from using the definition of $\xi_{t+1}$, the fourth equality from (4.5) and (4.8) which imply $V_{u t+1}-\beta V_{u t+2}=E S_{t+1}$, and the last equality from substituting (4.9) for $E S_{t+1}$. Thus, the sequence $\left\{\xi_{t}\right\}_{t \geq 0}$ obeys (3.10).

QED 


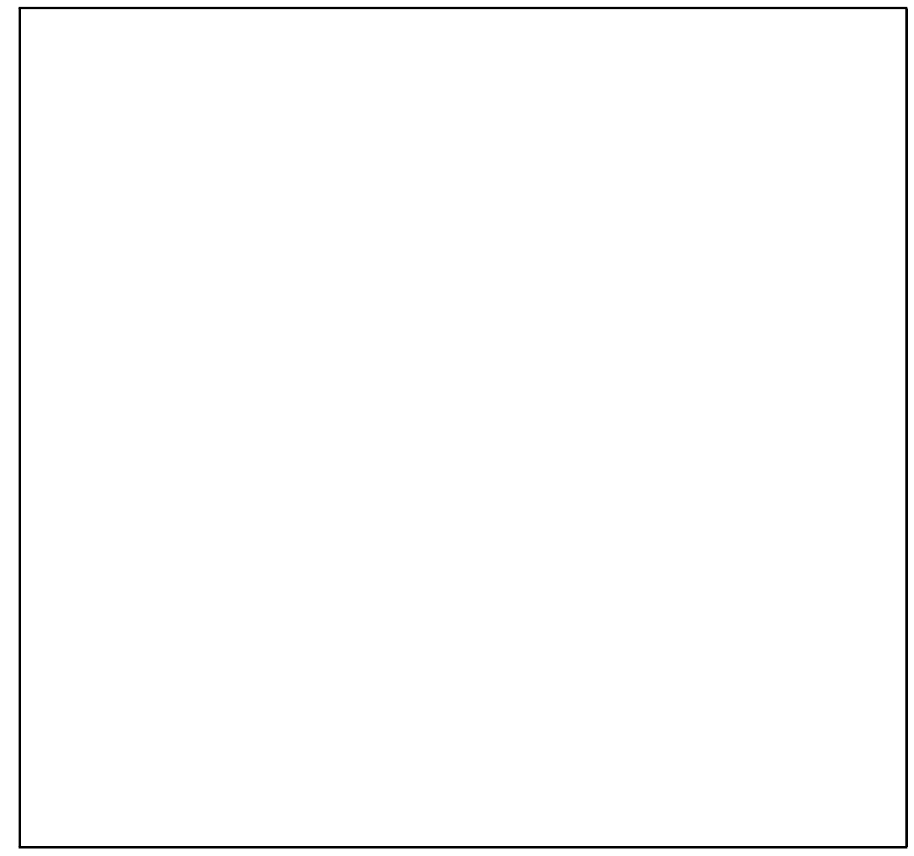

Figure 1 Efficient assignment and tightness 